\title{
Gabriela Rodrigues Vera
}

MODELAGEM TRÓFICA DO ECOSSISTEMA DE RESSURGÊNCIA DE

CABO FRIO, RIO DE JANEIRO

Tese apresentada ao Instituto Oceanográfico da Universidade de São Paulo, como parte dos requisitos para obtenção do título de Doutor em Ciências, área de concentração Oceanografia Biológica.

Orientadora: Profa. Dra. Lucy Satiko Hashimoto Soares

São Paulo 
Universidade de São Paulo Instituto Oceanográfico

MOdeLAGEM TRÓFICA DO ECOSSISTEMA DE RESSURGÊNCIA DE CABO FRIO, RIO DE JANEIRO

Gabriela Rodrigues Vera

Tese apresentada ao Instituto Oceanográfico da Universidade de São Paulo, como parte dos requisitos para a obtenção do Título de Doutor em Ciências, área de concentração Oceanografia Biológica

Aprovada em _ _ _ _ 
Agradecimentos

Agradeço primeiramente à Profa. Dra. Lucy Satiko Hashimoto Soares pela orientação, assistência e dedicação durante o período de desenvolvimento desse trabalho. Agradeço também à amiga Lucy, pela paciência, conselhos, ensinamentos e discussões tão importantes para a minha formação acadêmica como pessoal durante os últimos 10 anos !!!

Ao Professor PhD Villy Christensen pela oportunidade de estágio e discussão dos resultados no Fishery Centre da University of British Columbia.

À assistência e amizade da Prafa. Dra. Carmen Lúcia Del Bianco Rossi-Wongtschowiski e Dr. Gonzalo Velasco que incentivavam a iniciativa desse trabalho.

Às minhas queridas amigas, indispensáveis, que estiveram e estarão sempre comigo, Mandita, Carol, Dani, Grazinha, Fran e Kikosa! Brigadissima!!! Obrigada pelas revisões e auxilio na finalização!!!! 
Aos amigos de lab, não mais "meninas da Lucy", mas sim meninas e meninos da Lucy, pela paciência e convívio tão gostoso, Carol, Juju, Leandro, Caio, André e Elisa.

À Gragrá, querida irmã; Jony, meu brother; Dr. Vera, Papi; D. Teresa, mãma; e D. Yvonne, Avuela querida. Obrigada pelo apoio e helps que foram importantes para que esse trabalho pudesse ser finalizado! E UFA !! Foi!

Ao Gabriel, por tornar a minha vida muito mais gostosa!!! Obrigada também pela revisão do texto e auxilio com as figuras. Tnks ;-)

Aos amigos da UBC pelo acolhimento no Canadá e auxílios durante o estágio, Chiara, Pablo, Isa e Massi, saudades de vcs... Não do Frio!

Às meninas da secretaria, Silvana e Ana Paula, não preciso nem dizer né? Vcs foram ótimas!

Obrigada ao Seu Pedro, que com muita paciência e atendimento ao meu desespero, encaderna a tese com cuidado e agilidade!!!! Aos professores e funcionários do Instituto Oceanográfico pelo apoio.

À FAPESP pelo auxilio recebido. 
Toda a nossa ciêncía, comparada com a realidade, éprimitiva e infantíl

- e, no entanto, é a coisa maís preciosa que temos."

(Albert Einstein) 
À vida, que me trouxe até aquí, e apaíxonada. 
ÍNDICE

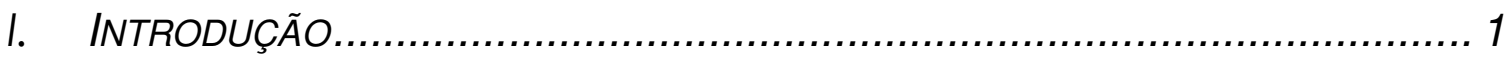

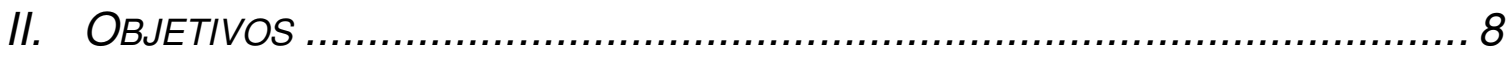

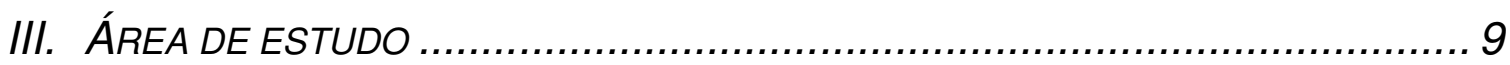

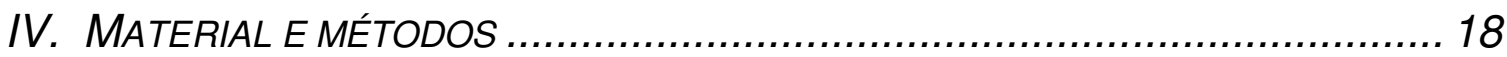

IV.1 Estrutura e bases do modelo ...................................... 18

IV.1.1 Estrutura matemática ................................................ 20

IV.2 Elaboração dos Modelos............................................ 24

IV.2.1 Construção dos Compartimentos do modelo ........25

IV.2.2 Dados de Entrada do Modelo ..................................... 29

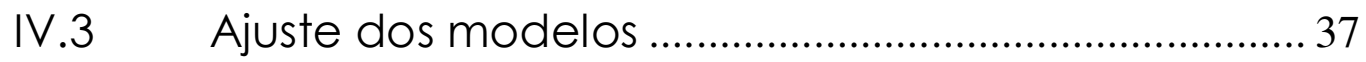

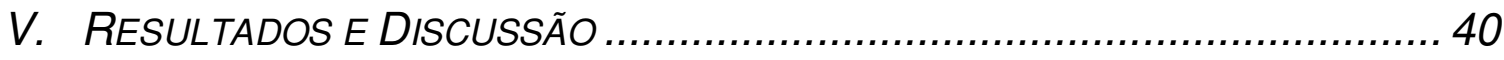

V.1 Modelos Sazonais.......................................................... 40

V.2 Modelo Médio Anual ................................................. 47

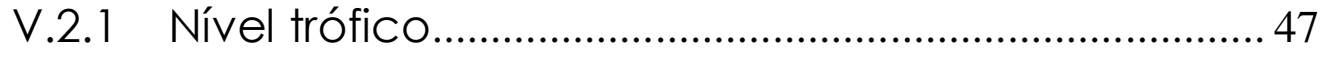

V.2.2 Parâmetros do modelo ................................................. 50

V.2.3 Atributos ecológicos do Ecossistema ......................... 53

V.2.4 Simulações dinâmicas dos Efeitos da Variabilidade

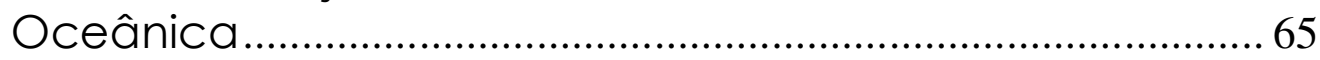

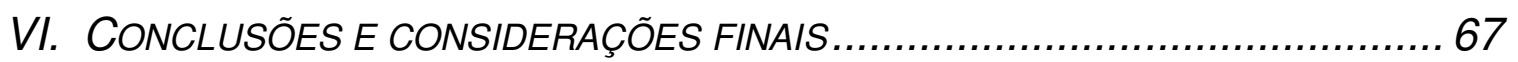

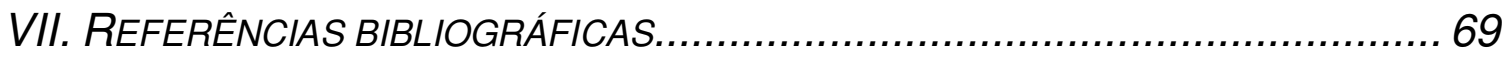




\section{Resumo}

Este trabalho teve como objetivos analisar a estrutura e funcionamento do ecossistema de Cabo Frio, levando-se em consideração a variação sazonal do fenômeno de ressurgência, através do modelo trófico Ecopath. Foram elaborados dois modelos sazonais (primavera-verão e outono-inverno) e um modelo médio anual. Os modelos sazonais apresentaram pouca diferença entre si, com exceção da biomassa dos produtores que é muito mais elevada no período de primavera-verão, quando a ressurgência é mais intensa. Essa pequena diferença pode ser explicada pela pouca variação sazonal nas dietas dos grupos do modelo e, possivelmente, pela indisponibilidade de dados de desembarque pesqueiro. O modelo anual foi considerado como representativo do sistema de Cabo Frio, cujos descritores ecológicos permitiram classificá-lo como um sistema em desenvolvimento com grau elevado de desorganização, característica comum para regiões de ressurgência. Caracterizou-se também por apresentar alta conectância e onivoria, caracterizando-o como um sistema de alta resiliência. O Nível trófico calculado pelo modelo foi semelhante ao nível trófico isotópico disponível na literatura de grupos tróficos similares confirmando a confiabilidade ao modelo gerado.

Palavras-chave: Modelagem trófica, Ecopath, Cabo Frio, Ressurgência. 


\begin{abstract}
The structure and trophic functioning of the ecosystem of Cabo Frio were analyzed considering the seasonal variation of the upwelling events. Two different seasonal models (Ecopath) and an annual model were constructed. The seasonal models did not show great differences, except for a higher biomass of producers during the spring-summer period, when the upwelling is more intense. Possibly, this difference was due to the small seasonal variation in the diet among trophic groups and lack of information on fishery catch data. The annual model could be considered as representative of the system of Cabo Frio, and according to the ecological descriptors it is a developing system with a high degree of disorganization, common characteristic in upwelling regions. The trophic levels calculated by the model were similar to the isotope trophic levels available in the literature for similar trophic groups, showing the confidence of the obtained results.
\end{abstract}

Key- world: Trophic modeling, Ecopath, Cabo Frio, Upwelling. 


\section{Lista de Tabelas}

Tabela 1: Limites termohalinos e espessuras das massas de água na região oceânica da Bacia de Campos (Silveira, 2007)

Tabela 2:Descrição dos grupos tróficos construídos para os modelos.

Tabela 3. Dados iniciais levantados para input no Modelo anual

Tabela 4: Matriz de dieta utilizada como entrada no modelo Ecopath.

Tabela 5: Parâmetros gerados pelo modelo sazonal baseado em dados de outono-inverno.

Tabela 6: Parâmetros gerados pelo modelo sazonal baseado em dados de primavera-verão.

Tabela 7: Parâmetros ecológicos gerados pelo modelo com base em dados sazonais.

Tabela 8: Comparação entre o nível trófico (NT) isotópico e o calculado pelo modelo.

Tabela 9: Parâmetros gerados pelo modelo baseado nos dados médios anuais Entre parênteses dados gerados pelo modelo

Tabela 10: Parâmetros ecológicos gerados pelo modelo com base em dados médios anvais. 


\section{Lista de Figuras}

Figura 1. Mapa da costa sudeste do Brasil, demonstrando a configuração da linha de costa e a batimetria do relevo oceânico. Em destaque, circulado, a região de estudo.

Figura 2: Mapa da região de Cabo Frio, com indicação da área coberta pelo modelo (503 Km-2).

Figura 3:Esquema ilustrativo: Imagem da temperatura da superfície do mar identificando os meandramentos da corrente do Brasil com a formação dos vórtices na região de Cabo Frio (Silveira, 2007). 13

Figura 4: Esquema simplificado da movimentação das massas d'água durante a ressurgência costeira (por Lucien Silvano Alhanati). 14

Figura 5: figura esquemática de representação da intrusão da ACAS na plataforma durante o Verão. Modificado de Matsuura \& Pires-Vanin (1993)

Figura 6: Diagrama de fluxo baseado em dados do modelo anual.O tamanho dos compartimentos é proporcional à biomassa e a espessura das linhas quantifica os fluxos (NT= nível trófico). 61

Figura 7: Diagrama de fluxo simplificado do sistema de Cabo Frio. 62

Figura 8: Matriz de impactos tróficos gerada a partir do modelo médio anual., 64

Figura 9: Simulação da variação das biomassas dos grupos tróficos em resposta a variação do fitoplâncton considerando vulnerabilidade $=1$ para os predadores. 


\section{INTRODUÇÃO}

Os ecossistemas marinhos, cada vez mais, têm sofrido exploração de seus recursos e ambientes. As principais ameaças à conservação e aproveitamento sustentável dessas regiões são as atividades relacionadas à especulação imobiliária, ao turismo predatório, às atividades portuárias e de extração de petróleo, bem como o aumento do esforço de pesca por barcos com tecnologias mais efetivas.

Esses fatores já acarretaram em diminuição de diversas populações de organismos marinhos, tendo-se registros de colapsos de estoques pesqueiros mais pronunciados em regiões litorâneas e costeiras (Worm, 2006). Um número representativo de espécies marinhas encontra-se sobrexplotadas ou em perigo de sobrexplotação (FAO, 2008; IBAMA, 2004; Rossi-Wongtschowiski et al., 2009) o que torna necessário adequação de políticas de manejo para que seja garantida a saúde desses ambientes.

A administração dessas atividades demanda uma visão holística do ambiente marinho e, buscando manter a extração dos recursos dentro dos limites sustentáveis e a fim de resolver os conflitos de exploração, deve-se melhor compreender a dinâmica e as interações do sistema ecológico/econômico combinados, respeitando critérios da sustentabilidade para a esfera natural (capacidade da regeneração) e 
socioeconômica (lucros, emprego, e coesão social) (BenDor et al., 2009).

Na esfera natural, que compreende as interações ecológicas, segundo recomendação da FAO para proteção dos ecossistemas marinhos, devem ser esclarecidos os fatores ambientais e a variabilidade natural para que os impactos da pesca e de outras atividades predatórias possam ser reduzidos, promovendo a conservação da biodiversidade e a proteção de espécies em vias de extinção (Garcia e Cochrane, 2005). Para tal, é indispensável o entendimento das relações entre as espécies e dessas com o ambiente, e a definição das características e dos limites do ecossistema.

O ecossistema segundo Odum (1988) é definido como a unidade que abrange os organismos interagindo entre si e com 0 ambiente físico, apresentando estrutura biótica e ciclagem de matéria de forma a apresentar características individuais e diferentes da soma de suas partes. Essas características, chamadas de emergentes, são consequência de processos autoreguladores e, portanto, emergem da análise do ecossistema como uma unidade (Angelini e Gomes, 2008).

Para a caracterização do ecossistema como a unidade proposta por Odum (op. cit.) são necessários dados consistentes que possam garantir a compreensão dos processos envolvidos. É nesse contexto que se insere a modelagem ecológica, atuando como uma ferramenta provedora dessas informações que servem de base para planos os de 
manejo e gerenciamento ambiental (Jorgensen, 1994), podendo-se estimar as propriedades emergentes de um ecossistema sem necessidade de se conhecer todas as partes componentes, proporcionando a compreensão do todo antes das partes (Odum et al., 1988). O uso dos modelos ecológicos torna-se fundamental se considerarmos o ganho de tempo frente a situações que necessitam de medidas mitigadoras rápidas, possibilitando a investigação de sistemas complexos, revelando suas propriedades, identificando lacunas no conhecimento científico e auxiliando na determinação de prioridades de pesquisas (Jorgensen,1994).

A análise dos ecossistemas através de modelagem se insere também entre os objetivos do Global Ocean Ecosistem Dynamics (GLOBEC), centrados principalmente na compreensão da produtividade do ecossistema, na identificação da posição trófica, do papel ecológico de cada espécie e nos mecanismos de conservação e recrutamento de espécies dominantes (Anónimo, 1999).

Os modelos ecológicos ecossistêmicos se baseiam em modelos matemáticos menos complexos, que permitem uma descrição holística do ecossistema embasado nos atributos de dinâmica da teia trófica. $\bigcirc$ Ecopath "modelo ecotrófico de equilíbrio de biomassa" foi desenvolvido a partir dessa base no intuito de descrever quantitativamente o funcionamento de ecossistemas de acordo com suas relações tróficas e está sendo utilizado com sucesso para descrição 
dos ecossistemas aquáticos (Christensen e Pauly, 1993, 1995; Chen et al., 2008; Heymans et al., 2009; Christensen et al., 2009; Karpouzi et al., 2009; Pirodri et al., 2009).

O Ecopath foi desenvolvido inicialmente por Polovina e Ow (1983) e Polovina (1984, 1985), que propuseram um modelo numérico que considera o sistema em estado de equilíbrio, com armazenamentos e fluxos constantes e balanço entre entradas e saídas. Em 1992, Christensen e Pauly desenvolveram uma nova versão, combinando esse conceito de "estado de equilíbrio" à técnicas derivadas da análise do fluxo de energia no ecossistema proposta por Ulanowicz (1986), no qual a biomassa dos principais componentes do sistema, suas interações tróficas quantitativas e a extração dessa biomassa por pesca são informações básicas (Christensen et al., 2000; Christensen e Walters, 2004).

As limitações do uso do Ecopath são consequência da premissa de estado estável, ou seja, "de equilíbrio" na qual o modelo está baseado. De acordo com Jorgensen (1994) os modelos estáticos são incapazes de representar os estados em desequilíbrios e, por considerar médias de biomassas e fluxos pela unidade temporal adotada, o modelo resultante expressa apenas uma possibilidade dentre inúmeras outras. No entanto, esse autor recomenda a elaboração inicial de um modelo estado estável para áreas com conhecimentos escassos e, a partir deste, elaborar simulações dinâmicas. Além de preencher essa lacuna, 
a elaboração de modelos estáticos com novas informações desenvolvidas na área permite a geração de séries temporais de dados do sistema, o que por si só torna-se uma importante ferramenta a ser utilizada no manejo dos recursos.

Como a base dos modelos tróficos é o funcionamento do fluxo trófico entre os compartimentos e destes com o ambiente, essas relações alimentares são característica fundamentais. A teia trófica é uma representação das relações alimentares entre predadores, presas e o ecossistema (Pimm, 1982) e como os recursos alimentares e os predadores estão entre os principais fatores limitantes do crescimento populacional de qualquer espécie, as interações tróficas são informações essenciais para $\circ$ entendimento da dinâmica das populações e padrões emergentes de diversidade (Levin, 1970; Tokeshi, 1999; Giacomini, 2007).

Vários modelos de ecossistemas aquáticos brasileiros, com abordagem ecotrófica, foram gerados (Angelini e Petrere, 1996, Telles 1998, Rocha 1998, Rocha et al., 1998, Vasconcellos 2000, Vasconcellos e Gasalla, 2001, Gasalla, 2004, Gasalla e Rossi-Wongtschowski, 2004, Velasco e Castello, 2005), entretanto, nenhum modelo do ecossistema de ressurgência de Cabo Frio foi produzido até o momento.

A região de Cabo Frio se caracteriza por apresentar dinâmica oceanográfica diferenciada, sendo o único ambiente de intensa ressurgência costeira ao longo do litoral brasileiro (Valentin, 1984; Silveira 
et al., 2000; Carbonel, 2003; Castelão et al., 2004). Sistemas de ressurgência costeira são caracterizados por possuírem grandes estoques de peixes (FAO, 2005) e serem intensamente explorados, sendo que muitos deles já apresentam efeitos diretos e indiretos de sobrexplotação em seus estoques (Pauly et al., 1998; Wolff, 1994; Moloney et al., 2005). Em decorrência disso, esses sistemas têm sido, nas ultimas décadas, objeto de diversos estudos sobre sua estrutura e funcionamento para entendimento das características hidrodinâmicas e da produtividade biológica, de maneira a gerar informações que possam embasar políticas de gerenciamento e administração da exploração sustentada dos recursos.

A administração dos recursos marinhos é também uma preocupação brasileira e, embora a ressurgência de Cabo Frio atinja área menor comparada aos grandes ecossistemas de ressurgência como Peru, Chile e África do Sul, o incremento na produção biológica local proporcionada pela ressurgência é muito importante para a região (Moreira da Silva, 1973) e merece atenção dos órgãos responsáveis pelo manejo de regiões marinhas.

Cabo Frio é um importante centro de pesca do Estado do Rio de Janeiro e um dos principais pólos produtivos do Estado (SEBRAE-RJ, 2009), destacando-se a produção da sardinha-verdadeira (Sardinella brasiliensis), da cavalinha (Scomber japonicus), do xerelete (Caranx 
crysos), do espada (Trichiurus lepturus), entre outros pescados (PROzEE 2005).

No intuito de caracterizar a estrutura e o funcionamento do ecossistema, e avaliar a influência da ressurgência na trama trófica de Cabo Frio, foi proposta a construção do modelo trófico que representasse a trama local. Sabendo-se que regiões de ressurgência apresentam características de sistemas em desenvolvimento, com alto grau de desorganização e altamente resilientes, foi levantada a hipótese de que o sistema de Cabo Frio se comportasse de maneira similar, e de que as relações tróficas estariam estruturadas de maneira a apresentar resposta aos eventos sazonais de ressurgência que disponibilizam grande quantidade de nutriente na zona eufótica.

Essa empreitada foi possível pela disponibilidade de dados gerados projeto institucional intitulado "Dinâmica do ecossistema de plataforma da região oeste do Atlântico Sul" (DEPROAS/PRONEX), executado pelo Instituto Oceanográfico da Universidade de São Paulo. 


\section{OBJETIVOS}

Objetivo geral

Esse projeto teve como objetivo a análise da estrutura e funcionamento trófico do ecossistema de Cabo Frio, levando-se em consideração a importância do fenômeno da ressurgência e sua variação sazonal.

\section{Objetivos específicos}

Analisar a estrutura e funcionamento do ecossistema de Cabo Frio através da elaboração de modelo trófico de massas balanceadas.

Analisar a influência da ressurgência e sua sazonalidade na cadeia trófica de Cabo Frio

Estimar parâmetros ecológicos do ecossistema de ressurgência de Cabo Frio, RJ.

* Identificar lacunas no conhecimento ecológico do sistema de Cabo Frio. 


\section{III. ÁREA DE ESTUDO}

O trabalho foi desenvolvido abrangendo a área de plataforma continental ao Largo de Cabo Frio, RJ (Figura 1), entre as latitudes de

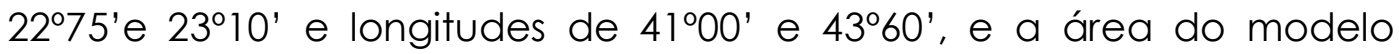
restringiu-se até a isóbata de 100m, totalizando uma área de 503 km² (Figura 2).

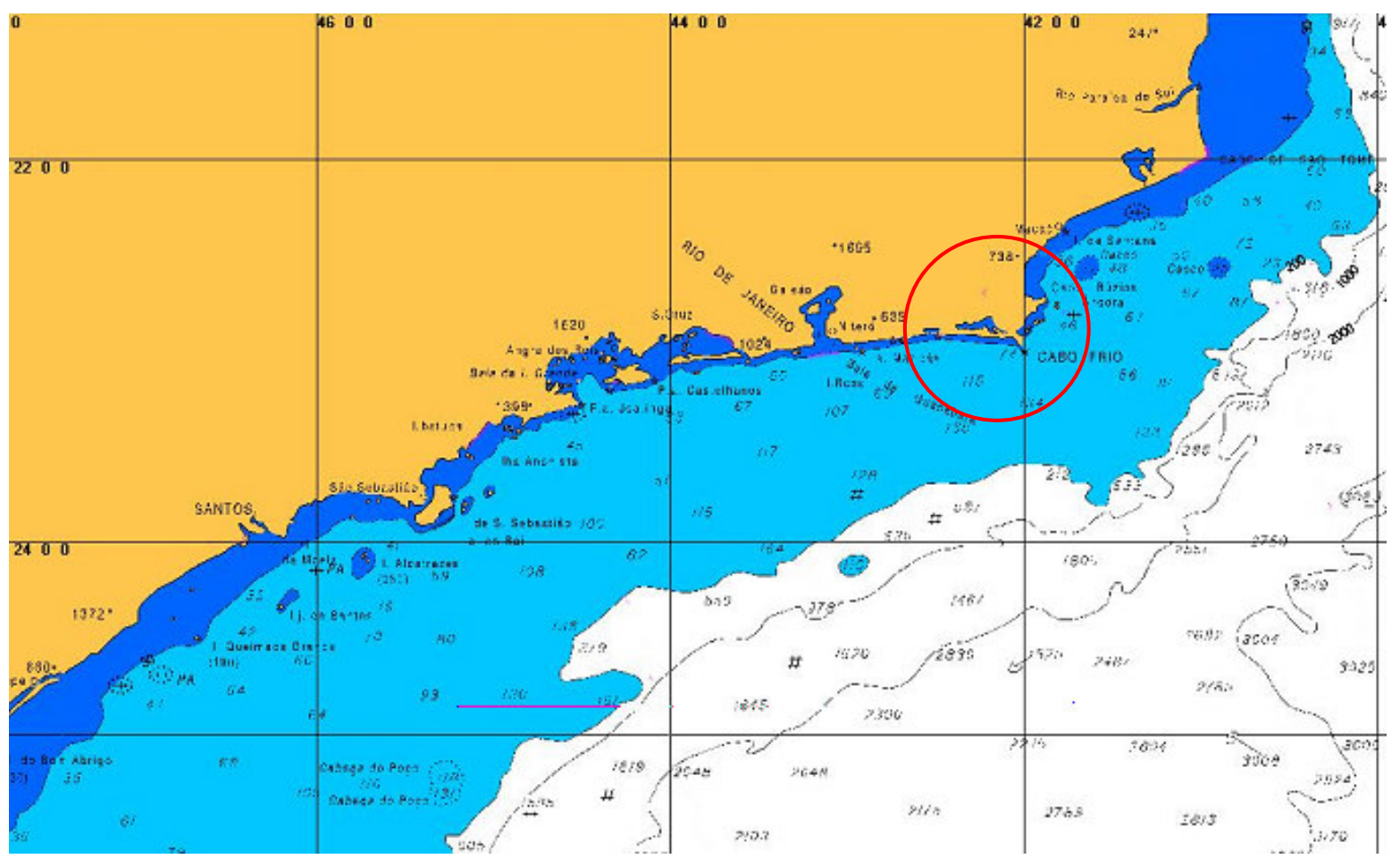

Figura 1. Mapa da costa sudeste do Brasil, demonstrando a configuração da linha de costa e a batimetria do relevo oceânico. Em destaque, circulado, a região de estudo. 


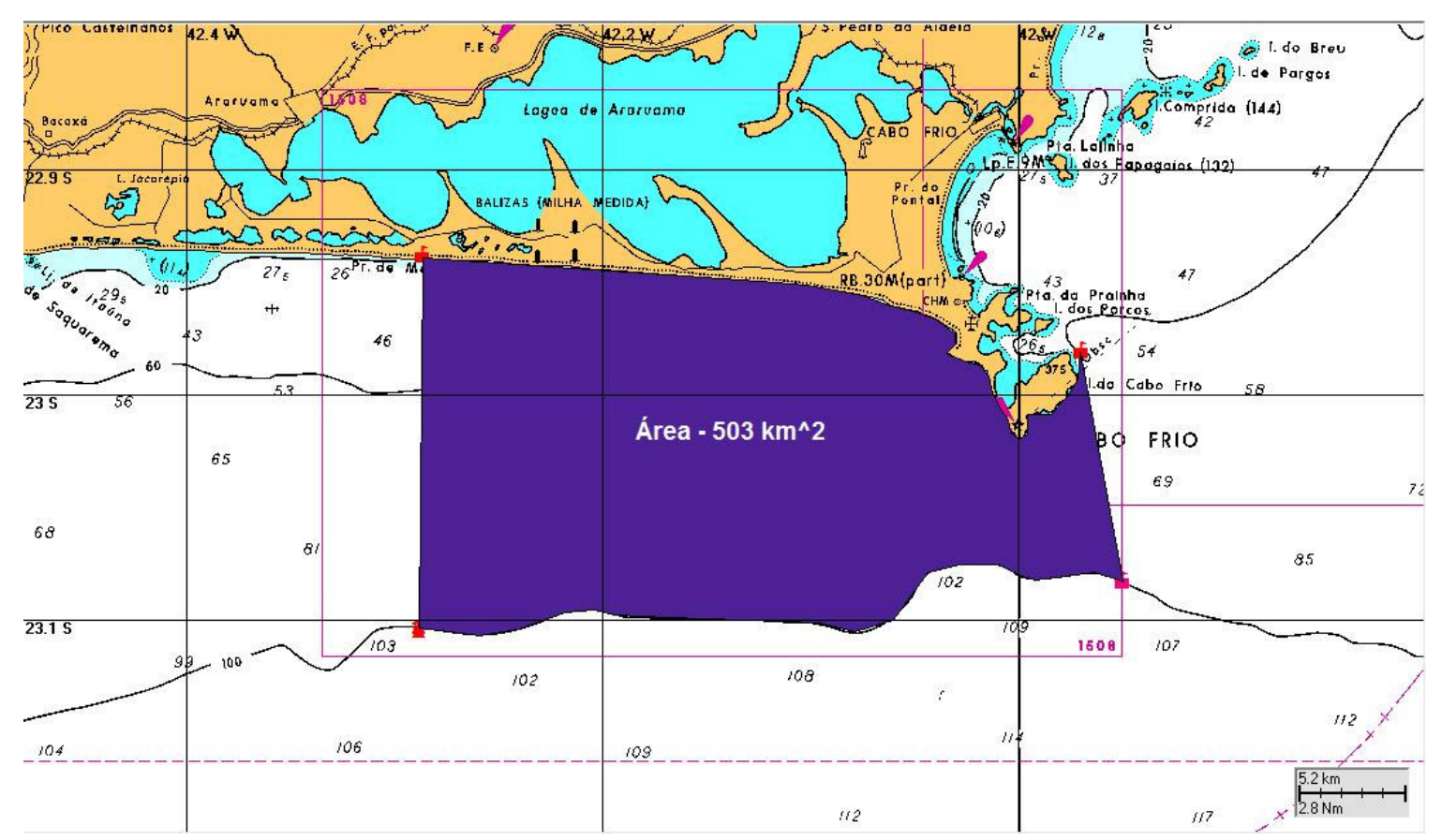

Figura 2: Mapa da região de Cabo Frio, com indicação da área coberta pelo modelo (503 Km-2).

A área está localizada na plataforma continental da região sudeste do Brasil, no estado do Rio de Janeiro, com largura em torno de 50 km e cuja principal característica fisiográfica é a mudança na linha de costa, que de Norte-Sul passa para Leste-Oeste (Zembruscki, 1979).

Em relação à composição do fundo, a região apresenta dois domínios bem definidos, sendo a região da plataforma até $50 \mathrm{~m}$ de profundidade composta por sedimento de origem terrígena como lama e areias com fácies lamosas, enquanto que na quebra da plataforma o domínio é carbonático, onde são encontrados bancos isolados de algas calcárias em meio a fundos de areia e areia lamacenta. Essas formações calcárias são constituídas por algas rodofíceas calcificadas e 
incrustantes do gênero Lithothamnium, e estão associadas a eventos regressivos do nível do mar (Kempf, 1972).

Segundo Castro e Miranda (1998), a área apresenta mistura de três massas d'água: a Água Costeira (AC), que apresenta temperaturas elevadas e salinidade abaixo de 34; a Água Tropical (AT) caracterizada por temperatura acima de $20^{\circ} \mathrm{C}$ e salinidade superior a 36 , localizada na camada superficial da coluna d'água; e a ACAS com temperatura inferior a $20^{\circ} \mathrm{C}$ e salinidade maior que 35 (Tabela 1).

Tabela 1: Limites termohalinos e espessuras das massas de água na região oceânica da Bacia de Campos (Silveira, 2007)

\begin{tabular}{cccc}
\hline Massa de água & Temperatura $\left({ }^{\circ} \mathrm{C}\right)$ & Salinidade & Espessura $(\mathrm{m})$ \\
\hline AT & $>20$ & $>36,20$ & $0-142$ \\
ACAS & $20,00-8,72$ & $36,20-34,66$ & $142-567$ \\
AIA & $8,72-3,46$ & $34,66-34,42$ & $567-1060$ \\
ACS & $3,46-3,31$ & $34,42-34,59$ & $1060-1300$ \\
APAN & $3,31-2,04$ & $34,59-34,87$ & $1300-3260$ \\
\hline
\end{tabular}

A AC é resultante da mistura das águas da plataforma e águas continentais, sendo caracterizada pela baixa salinidade e elevadas temperaturas, sofrendo ação direta de ventos e marés que proporcionam uma mistura intensa (Castro e Miranda, 1998).

A AT ocupa os primeiros $150 \mathrm{~m}$ da coluna de água e suas características são resultantes principalmente da evaporação causada pela radiação solar intensa na região de sua formação (10Sul). Essa massa d'água é transportada pela Corrente do Brasil (CB) de norte para 
sul, margeando a quebra da plataforma até $22^{\circ} \mathrm{Sul}$, onde se descaracteriza pela influência das baixas temperaturas atmosféricas da região (Silveira et al., 2000).

A ACAS se forma na Zona de Convergência Subtropical (entre $30^{\circ}$ e $40^{\circ} \mathrm{Sul}$ ) pelo afundamento de águas que sofreram resfriamento e tornaram-se mais densas e são misturadas às águas mais frias, entra no giro subtropical através das Correntes do Atlântico Sul e da Benguela, chegando à costa da América do Sul transportada pela Corrente Sul Equatorial. A partir daí, parte da ACAS é carregada pela CB nas porções entre 100 e $800 \mathrm{~m}$ de profundidade (subsuperfície), abaixo da AT (Castro e Miranda, 1998; Santos, 2004).

A circulação oceânica na região é dominada pela CB, fluindo para o sul ao largo do sudeste brasileiro. Na região de Cabo Frio a CB apresenta meandramentos próximos a isobata de 200 metros (Campos et al., 1999) ilustrados na Figura 3. Campos et al. (1995) atribuiram a ocorrência destes meandros e vórtices às mudanças de orientação da costa e ao gradiente topográfico de fundo (plataforma estreita e abrupta ao norte de Cabo Frio, mais extensa e suave ao sul). Estes meandros e vórtices ocorrem na região entre a plataforma continental e oceano profundo e atuam como uma importante forma de comunicação entre as regiões, transportando nutrientes de regiões profundas para zonas eufóticas dando suporte a produtividade biológica sobre a plataforma continental. 


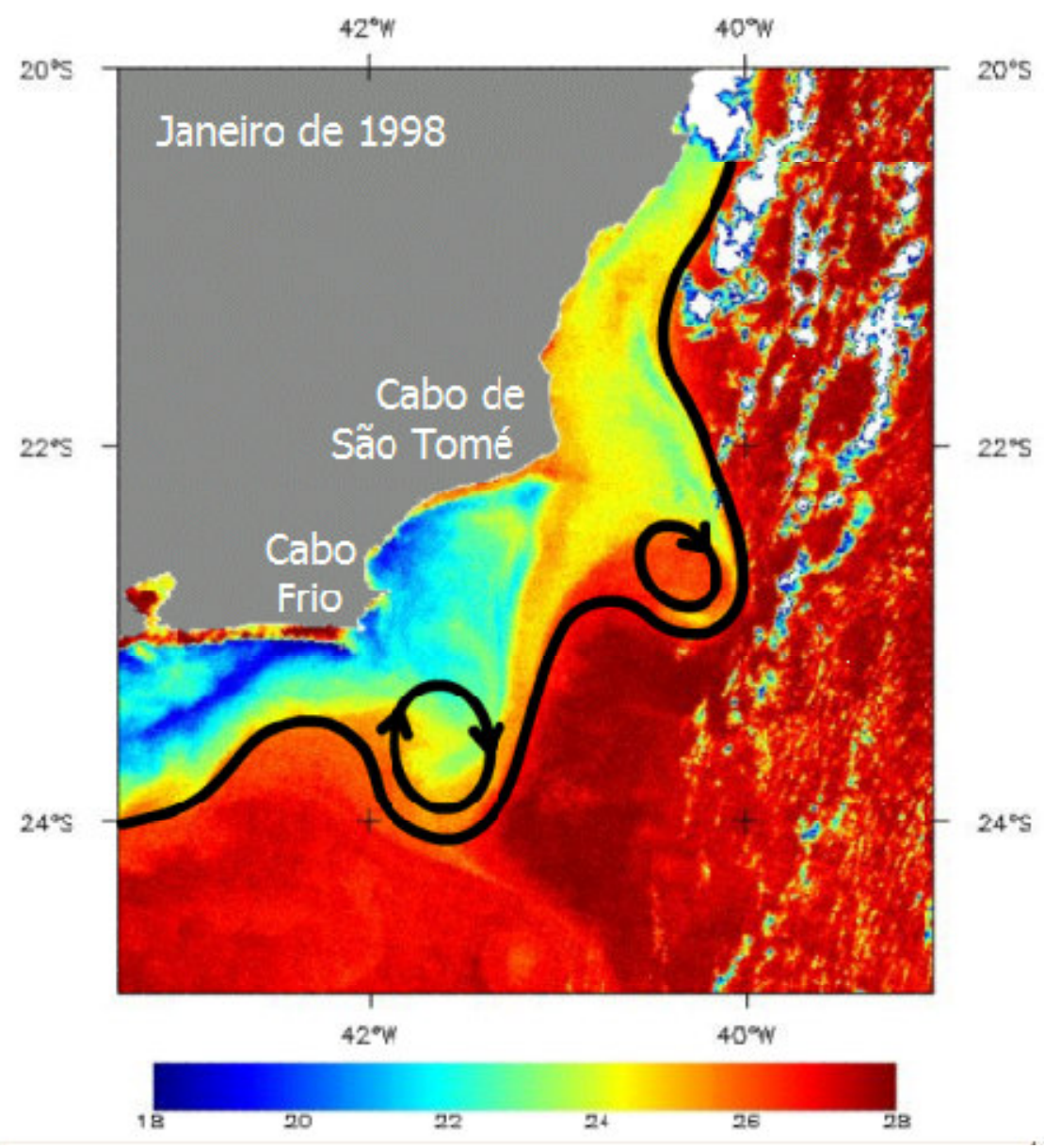

Figura 3:Esquema ilustrativo: Imagem da temperatura da superfície do mar identificando os meandramentos da corrente do Brasil com a formação dos vórtices na região de Cabo Frio (Silveira, 2007).

Outro importante fator dinâmico atuante na região está associado ao regime de ventos de nordeste (NE). A predominância dos ventos de NE na região é devida ao centro atmosférico de alta pressão semipermanente sobre o Oceano Atlântico Sul (Stech e Lorenzzetti, 1992), que induz um giro atmosférico anti-ciclonico de larga escala que predomina ao longo de toda a costa sudeste do Brasil. Este padrão apresenta uma variabilidade sazonal significativa com uma intensificação dos ventos no verão em relação ao inverno, onde o 
aumento do numero de sistemas frontais na região acaba por perturbar o padrão de NE.

Assim, a mudança de orientação da linha de costa do litoral da costa Sudeste, criando uma zona de divergência entre a linha de costa e a $C B$ e facilita o transporte de águas de sub-superfície para a superfície, associada à ação dos intensos ventos de nordeste durante o verão, que induzem um fluxo das águas da plataforma para região oceânica (Figura 4), são os fatores responsáveis pelo fenômeno de ressurgência costeira de Cabo Frio (Valentin, 1984; Silveira et al., 2000; Carbonel, 2003; Castelão et al., 2004).

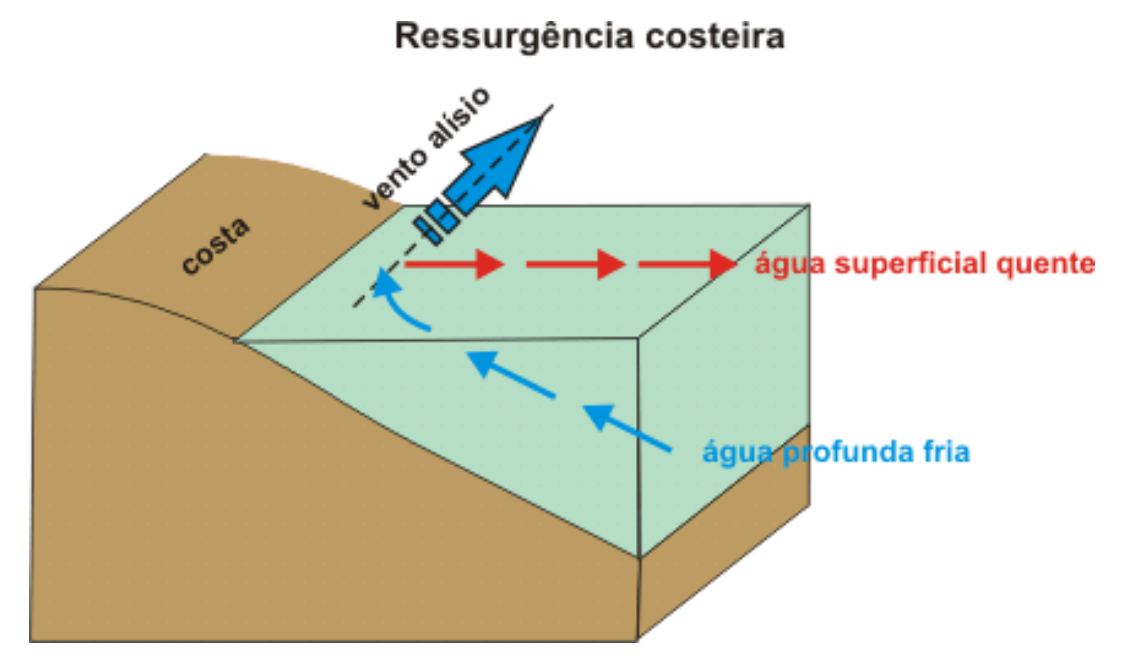

Figura 4: Esquema simplificado da movimentação das massas d'água durante a ressurgência costeira (por Lucien Silvano Alhanati).

Essa ressurgência apresenta variação sazonal devido às mudanças na intensidade dos ventos apresentada, na Figura 6 estão 
representadas as diferentes estações do ano e a movimentação das massas d'água. Durante o verão, quando os ventos predominantes de nordeste são mais intensos, ocorre um deslocamento das águas continentais superficiais em direção à região oceânica, que proporciona o afloramento ou ressurgência da Água Central do Atlântico Sul (ACAS) na plataforma continental. Nos meses de inverno, os ventos de nordeste diminuem de intensidade e a ACAS recua em direção à margem da plataforma, tornando a distribuição da temperatura na zona costeira mais homogênea, com águas entre 20 e 25ㄷ (Matsuura, 1986; Castro e Miranda, 1998; Castelão et al., 2004). 

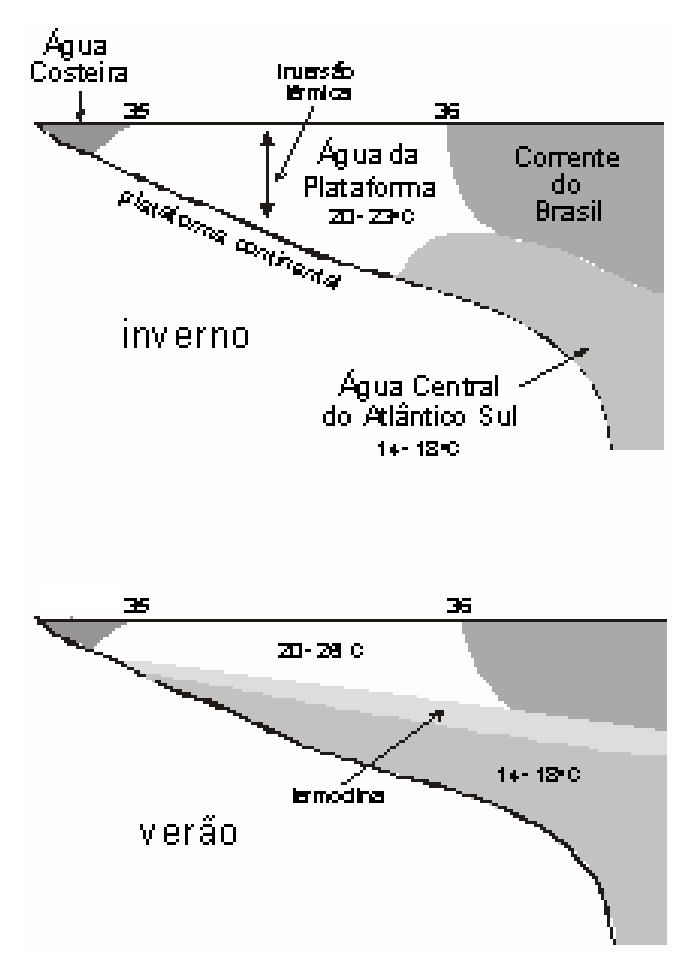

Figura 5: figura esquemática de representação da intrusão da ACAS na plataforma durante o Verão (Matsuura \& Pires-Vanin 1993)

Segundo Gonzales-Rodrigues et al. (1992), o afloramento da ACAS durante o verão em Cabo Frio favorece o enriquecimento das águas da zona eufótica, proporcionando assim um aumento da produção primária fitoplanctônica e, consequentemente, um incremento de toda a trama trófica da região. Os autores sugerem também que durante o inverno a cadeia é sustentada principalmente pela biomassa de detritos, dessa forma, a dinâmica das massas de água dessa região possivelmente proporciona alterações sazonais nas relações tróficas do ecossistema através da variação na disponibilidade de recursos alimentares. Ainda durante o verão, são frequentes as passagens de 
frentes frias que causam a interrupção da ressurgência, de modo que o fenômeno passa a ocorrer em ciclos de ressurgência e subsidência (Gonzales-Rodriguesz et al., 1992), o que provoca alterações na produtividade primária local através do empilhamento de águas mais quentes e pobres em nutrientes ao longo da costa (Valentin, 1984). 


\section{MATERIAL E MÉTODOS}

A seguir são descritos os métodos utilizados para a avaliação da dinâmica trófica da região de Cabo Frio, RJ e a descrição da área de estudo.

\section{1 ESTRUTURA E BASES DO MODELO}

O modelo Ecopath II adaptado por Christensen e Pauly (1992) a partir do Ecopath I, desenvolvido por Polovina e Ow (1983) e Polovina (1984, 1985), visa descrever a estrutura, estimar a biomassa e a produção de um ecossistema. Esse modelo está fundamentado nos conceitos de "estado de equilíbrio" energético, com técnicas derivadas da análise de fluxos de energia no ecossistema propostas por Ulanowicz (1986), ou seja, a biomassa de um determinado componente ao final de um período é igual ao valor da biomassa no começo desse período mais a produção de nova biomassa menos o que foi consumido. A equação simplificada, que segue o princípio da termodiâmica, pode ser escrita dessa maneira:

CONSUMO = PRODUÇÃO + RESPIRAÇÃO + ALIMENTO NÃO ASSIMILADO 
No modelo Ecopath as equações lineares pelas matrizes correspondentes são resolvidas através do "método inverso generalizado" (GIM) (Christensen e Pauly, 1992). Este cálculo só não é possível quando o determinante da matriz é zero ou se a matriz não é quadrada. Vários algorítimos foram incluídos para calcular alguns parâmetros desconhecidos sem utilizar o método de inversão generalizada (Christensen \& Pauly, 1992).

Dentre os parâmetros principais de entrada necessários para cada grupo do sistema, podemos suprimir um valor e obtermos posteriormente sua estimativa através do programa.

A principal exigência no processo de escolha do sistema a ser modelado é a quantidade de interações entre os elementos dentro do sistema. Ela deve ser muito maior que as interações desse sistema com o meio externo ou sistemas adjacentes. Os compartimentos a serem consideradas, podem ser espécies relacionadas ecologicamente ou taxonomicamente, espécies únicas ou grupo de idade e tamanho desta espécie, são recomendados no mínimo dez grupos para que sejam alcançados resultados satisfatórios (Christensen e Pauly, 1992).

Nesse trabalho foi utilizada a rotina "Ecopath" do aplicativo "Ecopath with Ecosim", versão 6.0, disponibilizado gratuitamente pelo Fisheries Centre da University of British Columbia, ("www.Ecopath.org"). O programa é constituído basicamente de duas partes: o 
balanceamento de um sistema de equações lineares e a análise dos fluxos de energia entre os elementos do ecossistema.

\section{IV.1.1 ESTRUTURA MATEMÁTICA}

O modelo é constituído por um sistema de equações lineares que, para um dado grupo (i) do ecossistema, em um dado intervalo de tempo, pode ser representado por:

Bi. $(P / B) i . E E i-Y i+\Sigma B j \cdot(Q / B) j . D C j i=0$

Em um sistema em equilíbrio tudo que é produzido é consumido, não havendo acúmulo de biomassa; Bi é a biomassa do componente $i$ (presas) durante o período determinado; (P/B)i é a razão produção por biomassa de i; EEi é a eficiência ecotrófica, ou seja, a fração da produção (i) $[P=B$. (P/B)] que é consumida no sistema ou explorada pela

pesca; $Y i$ é o rendimento $[Y i=F i . B i$, sendo $F$ a mortalidade por pesca $] ; B j$ é a biomassa de consumidores ou predadores (j); (Q/B) é o consumo por unidade de biomassa de (j) e DCji é a fração da presa (i) na dieta do predador (j).

As entradas requeridas pelo programa são:

- $\quad$ Produção primária (PP); 
- $\quad$ Biomassa (B);

- $\quad$ Eficiência ecotrófica (EE);

- $\quad$ Exportação ou captura por pesca;

- $\quad$ Produção por biomassa (P/B);

- $\quad$ Consumo alimentar por biomassa (Q/B);

- $\quad$ Composição da dieta (DC);

O Ecopath é o primeiro módulo oferecido no pacote "Ecopath with Ecosim" e utiliza as informações citadas acima para a construção de um esquema do fluxo de energia do ecossistema no período de tempo a que os dados se referem.

O balanceamento do modelo é baseado na produção e no balanço de massa para cada grupo. Na maior parte dos casos, P/B equivale à taxa instantânea de mortalidade (Z) que é comumente estimada como parte da avaliação tradicional dos estoques pesqueiros (Allen, 1971, Christensen et al., 2000).

Cada compartimento (grupo trófico) do modelo deve ter as informações contidas na equação (1), podendo-se suprimir um dos parâmetros, para que o modelo possa estimar o parâmetro não conhecido. Estes parâmetros são os requisitos básicos e são introduzidos através de três matrizes: 
a) Matriz de Biomassa (B) e as taxas de consumo/biomassa (Q/B), Produção /biomassa (P/B) e Eficiência Ecotrófica (EE) de cada grupo trófico.

b) Matriz da dieta, em massa percentual, de cada grupo trófico (presa/predador), com exceção dos produtores e decompositores.

c) Matriz com dados de pesca, incluindo desembarques e descartes médios anuais.

O segundo módulo do pacote "Ecopath e Ecosim" utiliza a representação criada no Ecopath ( $\left.1^{\circ} \mathrm{módulo}\right)$ para avaliar diferentes cenários de perturbações ambientais, exploração por pesca ou de outras origens (acidentais, por exemplo) (Walters et al., 1997).

Partindo da equação 1, Walters et al. (1997) desenvolveram uma equação diferencial principal que permite a simulação de variações temporais dinâmicas da biomassa:

$$
\Delta \mathrm{Bi} / \Delta \mathrm{t}=g i \sum_{j} Q j i-\sum_{j} Q j i+I i-(M 0 i+F i+e i) B i
$$

Onde, Bi é a Biomassa; Mi é a mortalidade natural; $\mathrm{Fi}$ a mortalidade por pesca; gi a eficiência de crescimento do grupo (i); ei a 
taxa de emigração; li a taxa de imigração; Qij a taxa de consumo da presa (i) pelo predador (j).

Em Qij, é considerada a premissa de que as presas não estão constantemente disponíveis, ou seja, vulneráveis. Essa relação de vulnerabilidade é determinada no Ecosim (Christensen et al., 2000, Christensen e Walters, 2004) por uma taxa vij que se relaciona à taxa de consumo da seguinte forma:

$$
Q i j=v i j * a i j * B i * B j /\left(v i j+v{ }^{\prime} i j+a i j B J\right)
$$

Onde: $v$ = vulnerável; $v^{\prime}=$ não - vulnerável; aij é o tempo de busca do predador j pela presa (i) no ecossistema.

As simulações das variações nas relações tróficas desse trabalho foram feitas através da ferramenta "forcing function" aplicada aos produtores primários.

Os dados utilizados para os cenários foram os dados de temperatura da superfície do mar (TSM) que foram obtidos das análises de Reynolds et al. (2007) obtidos por satélite, a partir disso foi construído um grid (com fator de escala $=1,5$ ) de variação para analisar as respostas dos comportamentos e das relações tróficas. Assim foi utilizada apenas a variação e não os valores de temperatura como forçante. 


\section{IV.2 ELABORAÇÃO DOS MODELOS}

Foram construídos três modelos tróficos de massas balanceadas para representar as relações tróficas do sistema de Cabo Frio (RJ): dois modelos sazonais, considerando-se um período de seis meses para cada um deles, no intuito de detectar possíveis diferenças no funcionamento da dinâmica trófica associada ao regime sazonal da ressurgência na região e um modelo médio anual. Todos os dados inseridos no modelo estão expressos em $\mathrm{g} / \mathrm{m}^{2}$.

Os modelos sazonais seguiram o seguinte padrão: um representando as estações de Primavera e Verão, com alta produção primária e maiores biomassas dos outros níveis tróficos, e principalmente com a presença do grupo que inclui Salpas e Quetognatas ("Zooplâncton II"). O segundo, representando as estações de Outono e Inverno com produtividade mais baixa, menores biomassas dos grupos e ausência do grupo "Zooplâncton II". Pauly e Christensen (1992) sugerem a construção de modelos médios anuais, no intuito de avaliar a representatividade desse modelo para a região, foram comparados os modelos sazonais com o modelo médio anual. 


\section{IV.2. I CONSTRUÇÃO DOS COMPARTIMENTOS DO MODELO}

A definição e a composição dos compartimentos tróficos foram baseadas na importância ecológica e/ou econômica dos componentes. Os dados dos peixes foram fundamentais para a construção do modelo, pois além de serem recursos explotados e de sua localização superior na teia alimentar, seus parâmetros populacionais eram disponíveis.

A composição dos compartimentos tróficos foi baseada principalmente em dados gerados no projeto DEPROAS "Dinâmica do ecossistema de plataforma da região oeste do Atlântico Sul", um projeto institucional desenvolvido pelo Instituto Oceanográfico da Universidade de São Paulo, cujo objetivo foi de entender os mecanismos físicos responsáveis pela ressurgência e suas influências no ecossistema de Cabo Frio (Soares', comunicação pessoal; De Leo, 2002; Furtado et al., 2002; Lopes et al., 2002 a,b; Pires-Vanin et al., 2002; Silveira et al., 2002; Soares et al., 2002; Tascheto e Wainer, 2002; Lopez e Soares, 2003; Manavella e Soares, 2003; Pucci, 2004; Castro-Filho e Gaeta, 2002; Muto, 2004; De Leo e Pires-Vanin, 2005; Sumida et al., 2005; De Leo e PiresVanin, 2002; Vera, 2006; Crété, 2007).

Os compartimentos estabelecidos para o modelo são formados por uma ou mais espécies com similaridade taxonômica ou ecológica,

\footnotetext{
${ }^{1}$ Soares, L.S.H. Profa. Dra. do Instituto Oceanográfico da Universidade de São Paulo.
} 
baseados principalmente nos grupos descritos por Soares et al. (em preparação) para a região de Cabo Frio através da análise de isótopos estáveis e composição da dieta. Foram gerados 21 grupos tróficos para representar a estrutura trófica do ecossistema de Cabo Frio no verão, sendo: 1 para produtores (fitoplâncton), 2 para zooplâncton (I e II), 14 grupos pertencentes ao nécton, 3 grupos representantes do bentos e por fim o Detrito que é "default" do modelo no pacote Ecopath e Ecosim 6.0.5.4. A composição desses grupos está detalhada na Tabela 2. O modelo que representa o período de outono e inverno foi gerado com apenas 20 grupos tróficos para representar a estrutura trófica durante essas estações, levando em consideração a ausência de um dos grupos zooplanctônicos durante esse período (Zooplancton II). 
Tabela 2: Descrição dos grupos tróficos construídos para os modelos.

\begin{tabular}{|c|c|}
\hline Grupos Ecopath & Espécies principais \\
\hline Zooplâncton I & Copepoda e copepoditos \\
\hline Zooplâncton II & Salpas e Chaetognatha \\
\hline \multirow{4}{*}{ Bentófagos I (crustáceos) } & Bellator brachichir \\
\hline & Mycteroperca microlepis \\
\hline & Prionotus nudigula \\
\hline & Prionotus punctatus \\
\hline \multirow{9}{*}{ Bentófagos II (poliquetas e ofiuróides) } & Dules auriga \\
\hline & Etropus longimanus \\
\hline & Eucinostomus argenteus \\
\hline & Mullus argentinae \\
\hline & Orthopristis ruber \\
\hline & Pagrus pagrus \\
\hline & Umbrina canosai \\
\hline & Xystreurys rasile \\
\hline & Zapteryx brevirostris \\
\hline Raneya brasiliensis & Raneya brasiliensis \\
\hline \multirow{9}{*}{$\begin{array}{l}\text { Comedores de invertebrados } \\
\text { bentônicos e peixes }\end{array}$} & Bembrops heterurus \\
\hline & Ctenosciaena gracilicirrhus \\
\hline & Micropogonias furnieri \\
\hline & Paralichthys patagonicus \\
\hline & Paralichthys triocellatus \\
\hline & Porichthys porosissimus \\
\hline & Rioraja agassizii \\
\hline & Urophycis brasiliensis \\
\hline & Urophycis mystacea \\
\hline \multirow{3}{*}{ Piscivoros bentônicos } & Gymnothorax conspersus \\
\hline & Gymnothorax ocellatus \\
\hline & Genypterus brasiliensis \\
\hline
\end{tabular}


Tabela 2: Continuação.

\begin{tabular}{ll}
\hline Lophius gastrophysus & Lophius gastrophysus \\
\hline Piscivoros pelágicos & Coriphaena hispidus \\
\hline Outros pequenos pelágicos & $\begin{array}{l}\text { Harengula clupeola, Opisthonema oglinum, } \\
\text { Cetengraulis edentulus }\end{array}$ \\
\hline Grandes bentófagos & Pseudopercis semifasciata \\
\hline Espada & Pseudopercis sp. \\
\hline & Trichiurus lepturus \\
Zooplanctófagos & Lycengraulis grossidens \\
& Trachurus lathami \\
\hline Pescadas & Scomber japonicus \\
& Caranx crysos \\
\hline Merluza & Cynoscion guatucupa \\
\hline Lulas & Cynoscion jamaicensis \\
\hline Sardinha & Merluccius hubbsi \\
\hline Camarões & Illex argentinus \\
\hline Bentos carnívoros & Loligo plei \\
\hline & Loligo sanpaulensis \\
\hline & Sardinella brasiliensis \\
\hline & Penaeus sp. \\
\hline
\end{tabular}


IV.2.2 DADOS DE ENTRADA DO MODELO

Os dados utilizados como parâmetros iniciais no modelo e as referências bibliográficas encontram-se anexos.

\section{IV.2.2.1 Biomassa}

Peixes: Para os peixes demersais, as biomassas foram estimadas através de dados de abundância das espécies gerados no projeto DEPROAS (Soares, rel. não publicado), através dos cálculos utilizando-se a área varrida (a):

$a j=t^{*} v^{*} h^{*} x$

Sendo:

aj= área varrida

$t=$ tempo de arrasto

$\mathrm{v}=$ velocidade de arrasto

h= comprimento da tralha de bóia

$x=$ taxa de conversão para $h$ para a distância da boca da rede $(0,42<X<0,66)$, tendo sido utilizado o valor 0,5 .

Assim pode-se calcular a captura por unidade de área:

Seja Cw a captura em peso efetuada por um arrasto. Então $\mathrm{CW} / \mathrm{t}$ é a captura em peso por hora, quando t é o tempo de arrasto (em horas). Seja (a) a área varrida. Então a/t é a área varrida por hora, e 


\section{$\mathrm{Cw}_{\mathrm{a} / \mathrm{t}}=\underset{\mathrm{a}}{\mathrm{Cw}} \mathrm{kg} / \mathrm{mm}^{2}$}

Cw é captura em peso efetuado por um arrasto.

$T=$ tempo de arrasto

$\mathrm{a}=$ área varrida $\left(\mathrm{km}^{2}\right)$

Assim chegou-se ao valor da Biomassa total da área através da fórmula:

Onde $\mathrm{A} \mathrm{m}^{2}$ é o tamanho total da área sob investigação.

$$
\mathrm{B}=\frac{(\overline{\mathrm{Cw} / \mathrm{a}})^{* \mathrm{~A}}}{\mathrm{X}}
$$

Para os peixes pelágicos, foram estimadas as biomassas através de dados de estatística pesqueira e/ou coletados em trabalhos específicos das espécies.

Bentos: Dados iniciais de biomassa dos organismos bentônicos são provenientes de trabalhos publicados do DEPROAS (De Leo, 2002; Sumida et al., 2005; De Leo e Pires-Vanin, 2005, De Leo e Pires-Vanin, 2006). 
Zooplâncton: A biomassa foi estimada pelo modelo e os parâmetros adotados foram baseados nos gerados por outros modelos (Jarre-Teichman et al., 1998; Shannon et al., 2004; Rocha et al., 2008).

Fitoplâncton: Em Cabo frio, Kampel (2003) encontrou valores de clorofila integrada na camada eufótica de $27,29 \mathrm{mg} \mathrm{m}^{-2}$ no inverno de 2001 e no Verão de 2002 a média encontrada foi $29,78 \mathrm{mg} \mathrm{m}^{-2}$. A produção primária integrada na zona eufótica alcançou valores de 0,81 $\mathrm{gCm}^{-2}, \mathrm{~d}^{-1}$ no inverno de 2001 e 1,56 gCm${ }^{-2} \cdot \mathrm{d}^{-1}$ no verão de 2002. Foi encontrado ainda manchas de produtividade que alcançaram 5 $\mathrm{gCm}^{2} \mathrm{~d}^{-1}$

Os dados de biomassa do fitoplâncton foram calculados utilizando-se o fator de conversão de 14,25 (Brown et al., 1991) de carbono para peso úmido.

A biomassa do detrito foi estimada são requeridos através da equação empírica, na qual é requerido dado de produção primária:

$\log _{10} D=0,95 \log _{10} P P+0,863 \log _{10} E-2,41 \quad$ (Pauly et al.,1993)

Onde $\mathrm{D}=$ detrito em $\mathrm{gCm}^{-2} ; \mathrm{PP}=$ produção primária em $\mathrm{gCm}^{2} \mathrm{ano}^{-1}$; $\mathrm{E}=$ profundidade da zona eufótica. 
Quando a biomassa não é conhecida, sugere-se utilizar a Eficiência Ecotrófica (EE), que é a fração da produção total consumida pelos predadores ou exportada do sistema. Assim, a biomassa das presas é determinada pela biomassa e consumo dos predadores no topo da cadeia alimentar, a produção não utilizada (1-EE) passa a ser considerada como fluxo para o detrito.

\section{IV.2.2.2 Parâmetros de crescimento (P/B) e consumo (Q/B)}

A produção refere-se ao aumento da biomassa dentro de um compartimento durante um dado período. Sempre que possível, a relação da produção/biomassa (P/B) utilizada foi calculada previamente para populações do mesmo local. Quando isto não foi praticável, os valores foram tomados da literatura (Anexo 1), tomandose cuidado especial para a utilização de valores que vêm de sistemas similares, priorizando a localização, as espécies, os gêneros e os sistemas de ressurgência nessa ordem. O P/B pôde ser obtido através de valores de mortalidade encontrados em literatura ou gerados por outros modelos.

O consumo é a quantidade de alimento predada por um grupo em um intervalo de tempo. A entrada no Ecopath é a relação do consumo com a biomassa (Q/B). Para a estimativa de $Q / B$, foi utilizada 
a equação empírica descrita em Palomares e Pauly (1998), utilizando-se dados de peso assintótico $\left(\mathrm{W}_{\infty}\right)$ do peixe segundo o modelo de Von Bertalanffy (Pauly, 1984), temperatura média do ambiente $\left({ }^{\circ} \mathrm{C}\right), \quad \mathrm{O}$ "aspect ratio" (A), relativo à forma da cauda do peixe e representativo do seu metabolismo (Palomares e Pauly, 1998) e dados da dieta (d e h = variáveis binárias para o tipo de dieta sendo $\mathrm{d}=0 / \mathrm{h}=1$ para herbívoros, $d=0 / h=0$ para os carnívoros e $d=1 / h=0$ para os detritívoros

$$
\left(Q / B=10\left(7,964-0,204 \log W_{\infty} \square-1,965 T+0,083 A+0,532 h+0,398 d\right)\right)
$$

Nos casos em que as essas estimativas não foram possíveis, utilizados os valores do coeficiente de conversão bruta (GEi) que relaciona a produção com o consumo de cada grupo (PB/QB). Para peixes o GEi deve variar entre 0,1 e 0,3 (Christensen et al., 2005). Abaixo estão os valores dos dados utilizados para entrada no modelo (Tabela 3). 


\begin{tabular}{|c|c|c|c|c|}
\hline Grupo trófico & $\mathrm{B}$ & $\mathrm{P} / \mathrm{B}$ & $Q / B$ & $\mathrm{EE}$ \\
\hline Lophius gastrophisus & 0,17 & 0,3 & 2,1 & \\
\hline Lulas & 3,76 & 1,95 & 3,9 & \\
\hline Piscivoros pelágicos & 1,70 & 1,35 & 2 & \\
\hline Espada & & 0,72 & 2,46 & \\
\hline Merluza & & 0,95 & 2,96 & \\
\hline Pescadas & 0,19 & 1,23 & 5,4 & \\
\hline Piscívoros bentônicos & 0,36 & 1,38 & 3 & \\
\hline $\begin{array}{l}\text { Comedores de invertebrados bentônicos e } \\
\text { peixes }\end{array}$ & 0,43 & 0,70 & 3,38 & \\
\hline Raneya brasiliensis & 0,09 & 0,72 & 3,8 & \\
\hline Bentófagos I & 1,50 & 0,38 & 2 & \\
\hline Bentófagos II & 0,62 & 1,16 & 3,8 & \\
\hline Zooplanctófagos & 2,30 & 2,80 & 13,8 & \\
\hline Outros pequenos pelágicos & 2,01 & 3,19 & 11 & \\
\hline Sardinha & & 3,60 & 20,3 & \\
\hline Zooplâncton II & & 40,00 & 54 & 0,15 \\
\hline Zooplâncton I & & 13,00 & 60 & 0,8 \\
\hline Camarão & & 5,20 & 33,3 & 0,8 \\
\hline Bentos carnívoro & 18,54 & 5,59 & 18,6 & \\
\hline Bentos depositívoro/detritívoro & 68,00 & 3,30 & 27,3 & \\
\hline Fitoplâncton & 29,65 & 115,70 & & \\
\hline Detrito & 11,23 & & & \\
\hline
\end{tabular}




\section{IV.2.2.3 Composição das Dietas}

As referências de composição da dieta utilizadas para a definição dos compartimentos dos consumidores (macrofauna bentônica e peixes) estão listadas no Anexo 3. Quando dados de proporção de massa das presas não foram encontrados, a porcentagem da ocorrência foi utilizada.

Na Tabela 4 está apresentada a matriz de dieta balanceada, contendo as presas e predadores, com exceção dos produtores e decompositores. 
Tabela 4: Matriz de dieta utilizada como entrada no modelo Ecopath.

\begin{tabular}{|c|c|c|c|c|c|c|c|c|c|c|c|c|c|c|c|c|c|c|c|}
\hline Presa \predator & 1 & 2 & 3 & 4 & 5 & 6 & 7 & 8 & 9 & 10 & 11 & 12 & 13 & 14 & 15 & 16 & 17 & 18 & 19 \\
\hline \multicolumn{20}{|l|}{ Lophius gastrophysus } \\
\hline Lulas & 0,050 & & 0,300 & 0,200 & & 0,150 & 0,065 & 0,002 & & & & & 0,135 & & & & & & \\
\hline Piscívoros pelágicos & 0,005 & & 0,000 & 0,025 & & & & & & & & & & & & & & & \\
\hline Espada & 0,050 & 0,085 & 0,100 & & & & 0,080 & & & & & & & & & & & & \\
\hline Merluza & 0,056 & & & & 0,050 & 0,015 & 0,050 & & & & & & & & & & & & \\
\hline Pescadas & 0,056 & 0,005 & 0,011 & & 0,025 & & 0,050 & & & & & & & & & & & & \\
\hline Piscívoros bentônicos & 0,150 & & & 0,050 & & & & 0,025 & & & & & & & & & & & \\
\hline $\begin{array}{l}\text { Comedores de invertebrados } \\
\text { bentônicos e peixes }\end{array}$ & 0,150 & & & 0,005 & & & 0,150 & & & & & & & & & & & & \\
\hline Raneya brasiliensis & 0,088 & & 0,015 & 0,003 & & & 0,015 & 0,003 & & & & & & & & & & & \\
\hline Bentófagos I & 0,150 & & & 0,050 & 0,150 & & 0,250 & 0,090 & 0,025 & & & & & & & & & & \\
\hline Bentófagos II & 0,150 & & & 0,020 & 0,150 & & 0,150 & 0,090 & 0,025 & & & & & & & & & & \\
\hline Zooplanctófagos & 0,000 & 0,150 & 0,200 & 0,050 & 0,025 & 0,150 & 0,100 & 0,000 & & & & & & & & & & & \\
\hline Outros pequenos pelágicos & 0,025 & 0,200 & 0,125 & 0,025 & 0,100 & 0,100 & 0,025 & 0,037 & & & & & & & & & & & \\
\hline Sardinha & 0,005 & 0,100 & 0,150 & 0,250 & 0,050 & 0,050 & 0,050 & & & & & & 0,050 & & & & & & \\
\hline Zooplâncton II & & 0,250 & & 0,200 & 0,095 & 0,250 & 0,000 & & & & & 0,500 & 0,400 & 0,050 & 0,075 & & & & \\
\hline Zooplâncton I & & 0,146 & & 0,000 & 0,000 & 0,105 & 0,000 & & & & & 0,400 & 0,150 & 0,250 & 0,600 & 0,050 & & & \\
\hline Camarão & 0,050 & 0,065 & & 0,000 & 0,150 & 0,150 & 0,015 & 0,250 & 0,150 & 0,650 & & & & & & & & 0,250 & \\
\hline Bentos carnívoro & 0,015 & & & & 0,055 & 0,015 & & 0,254 & 0,250 & 0,200 & 0,300 & & & & & & & 0,345 & \\
\hline Bentos depositívoro/detritívoro & & & & & & 0,015 & & 0,250 & 0,550 & 0,150 & 0,700 & & & & & & & 0,250 & \\
\hline Fitoplâncton & & & & & & & & & & & & 0,100 & & 0,700 & 0,325 & 0,950 & & & \\
\hline Detrito & & & & & & & & & & & & & & & & & 1,000 & & 1,000 \\
\hline Importação & & & 0,099 & 0,123 & 0,150 & & & & & & & & 0,265 & & & 0,000 & 0,000 & 0,155 & \\
\hline
\end{tabular}




\section{IV.2.2.4 Dados de pesca}

Os dados de pesca foram levantados dos relatórios anuais de estatística pesqueira disponibilizados pelo IBAMA (IBAMA, 2002, 2003) para a região do Rio de Janeiro, considerando-se a produção de Cabo Frio como sendo equivalente a $16 \%$ do total do estado para as principais espécies-alvo das pescarias locais como sugerido no censo estrutural da pesca do PROZEE (2005).

\section{IV.3 AJUSTE DOS MODELOS}

O ajuste dos modelos foi feito a partir de análise minuciosa das eficiências ecotróficas, que devem ter valores entre $0-1$, porém nem sempre os dados iniciais das matrizes geram valores compatíveis, sendo necessária a análise dos valores e a manipulação cuidadosa para que haja uma coerência matemática para o funcionamento desse ecossistema. As matrizes iniciais foram modificadas seguindo critérios de confiabilidade dos dados para que houvesse o balanceamento do modelo.

Inicialmente, após a entrada dos dados iniciais levantados, nenhum dos três modelos estava equilibrado (por exemplo, fluxo negativo para o detrito, eficiência ecotrófica maior que um (1), 
indicador de demanda de predação muito alta para ser sustentável, e $P / Q=G E$ que avalia relação fisiológica incompatível). A qualidade dos dados usados para cada grupo foi avaliada, atribuindo uma escala de menor a maior grau de incerteza de acordo com Christensen et al. (2004). As estimativas empíricas geradas com dados das amostras do DEPROAS, tomadas dentro da área dos modelos, foram consideradas como de menor grau de incerteza, e dados empíricos de outras áreas, de grau médio de incerteza; e às informações menos específicas foi atribuído maior grau de incerteza.

Dessa maneira, os dados de maior confiança foram os de biomassa das espécies de peixes demersais, de bentos e fitoplâncton. Embora as biomassas de camarões e lulas tivessem sido obtidas com dados do Deproas, elas estavam subestimadas e foram recalculadas pelo modelo. Foi o mesmo caso da maioria das biomassas dos grupos dos peixes pelágicos como a sardinha, os zooplanctófagos e outros pequenos pelágicos para os quais as biomassas foram ponderadas com dados de desembarque (IBAMA, 2002, 2003). A biomassa do zooplânton foi estimada pelo modelo.

Foi também necessário reavaliar os dados da matriz de dieta. Embasado na hipótese de variabilidade na composição e quantificação das presas, visto que a matriz foi construída a partir de dados levantados em estudos de conteúdo estomacal, que podem 
fornecer apenas uma situação estática da composição da dieta, pôdese ajustar a matriz incluindo presas possíveis. 


\section{Resultados e Discussão}

São apresentados resultados da organização trófica e caracterização do ecossistema de Cabo Frio para os meses de primavera e verão, representativos do período com maior intensidade dos eventos de ressurgência, para os de outono e inverno, de menor intensidade, e resultados para o sistema através de um modelo médio anual. Este último foi considerado bastante consistente e será discutido após a apresentação dos resultados gerais dos modelos sazonais.

\section{V.l Modelos Sazonals}

Os modelos sazonais diferiram-se principalmente pela maior produtividade primária durante o período de ressurgência mais intensa (primavera-verão) e o consequente incremento da biomassa dos organismos em toda a cadeia, bem como pelo grupo de organismos zooplanctônicos que incluiu as salpas e quetognatas presentes apenas nesse período (Zooplancton II) (Tabelas 4 e 5).

A diferença mais significativa entre os dois modelos foi sem dúvida a biomassa fitoplanctônica que no verão apresentou valores muito maiores do que no inverno (Tabelas 5 e 6). Confirmando esses dados, no verão de 2001 e 2002 Kampel (2003) detectou manchas de produtividade de até $5 \mathrm{gCm}-2 \mathrm{~d}-1$ em Cabo Frio, valor compatível ao de 
regiões de ressurgência com alta produção, inclusive pesqueira, como as ressurgências de Humbolt e Benguela (Jarre-Teichmann e Pauly, 1993; Shanon et al., 2004; Medina et al., 2007).

Esse alto valor da biomassa fitoplanctônica em Cabo Frio, associada à biomassa zooplanctônica estimada pelo modelo, acarretou uma baixa eficiência ecológica desse grupo no sistema, o que pode expressar uma super-estimativa da própria biomassa, já que os valores são calculados a partir de dados de produção primária, cuja produtividade tem escalas temporais menores (semanas) que a escala dos modelos. Portanto, a extrapolação dos valores de produtividade diária, mesmo que médios, para períodos maiores, não incluem, por exemplo, a possível passagem de frentes frias, que são muito comuns durante o verão na região e podem diminuir a taxa de produção (Valentin, 2001).

Outra explicação plausível seria a exportação da produção, pois segundo Kiorboe (1993) regiões com eventos de ressurgência podem apresentar exportação máxima de carbono através de sedimentação das células de fitoplâncton intactas, causada pela velocidade do crescimento fitoplanctônico que não é acompanhada pelos consumidores. No entanto, pode indicar uma grande capacidade de suporte da trama tróficos estando os valores das biomassas dos consumidores subestimados para a maior parte dos componentes tróficos do modelo. 
Tabela 5: Parâmetros gerados pelo modelo sazonal baseado em dados de outono-inverno.

\begin{tabular}{|c|c|c|c|c|c|c|}
\hline Grupo trófico & $\mathrm{NT}^{*}$ & $\mathrm{~B}$ & $\mathrm{P} / \mathrm{B}$ & $Q / B$ & $\mathrm{EE}^{*}$ & $P / Q^{*}$ \\
\hline Lophius gastrophysus & 4,5 & 0,07 & 0,12 & 0,84 & 0,00 & 0,14 \\
\hline Lulas & 3,6 & 2,11 & 0,78 & 1,56 & 0,77 & 0,50 \\
\hline Piscívoros pelágicos & 4,2 & 1,08 & 0,40 & 0,80 & 0,08 & 0,50 \\
\hline Espada & 3,8 & 1,45 & 0,32 & 0,98 & 0,55 & 0,33 \\
\hline Merluza & 3,9 & 0,08 & 0,48 & 1,18 & 0,94 & 0,41 \\
\hline Pescadas & 3,6 & 0,09 & 0,49 & 2,16 & 0,90 & 0,23 \\
\hline Piscívoros bentônicos & 4,3 & 0,02 & 0,55 & 1,20 & 0,90 & 0,46 \\
\hline $\begin{array}{l}\text { Comedores de invertebrados } \\
\text { bentônicos e peixes }\end{array}$ & 3,6 & 0,17 & 0,28 & 1,35 & 0,66 & 0,21 \\
\hline Raneya brasiliensis & 3,4 & 0,03 & 0,29 & 1,52 & 0,73 & 0,19 \\
\hline Bentófagos I & 3,2 & 0,24 & 0,35 & 0,80 & 0,67 & 0,44 \\
\hline Bentófagos II & 3,4 & 0,25 & 0,46 & 1,52 & 0,72 & 0,31 \\
\hline Zooplanctófagos & 3,0 & 1,04 & 1,12 & 5,52 & 0,90 & 0,20 \\
\hline Outros pequenos pelágicos & 3,0 & 1,90 & 1,28 & 4,40 & 0,47 & 0,29 \\
\hline Sardinha & 2,3 & 1,54 & 1,44 & 8,12 & 0,77 & 0,18 \\
\hline Zooplâncton I & 2,1 & 2,05 & 10,00 & 40,00 & 0,80 & 0,25 \\
\hline Camarão & 2,0 & 5,84 & 3,50 & 13,32 & 0,80 & 0,26 \\
\hline Bentos carnívoro & 3,2 & 7,42 & 2,24 & 7,44 & 0,51 & 0,30 \\
\hline Bentos depositívoro/detritívoro & 2,0 & 26,24 & 1,32 & 10,92 & 0,97 & 0,12 \\
\hline Fitoplâncton & 1,0 & 10,80 & 46,28 & 0,00 & 0,18 & \\
\hline Detrito & 1,0 & 0,24 & & & 0,68 & \\
\hline
\end{tabular}

$\mathrm{B}=$ Biomassa; $\mathrm{P} / \mathrm{B}=$ produção por biomassa; $\mathrm{Q} / \mathrm{B}=$ consumo por biomassa; $\mathrm{EE}=$ eficiência ecotrófica; *valores gerados pelo modelo 
Tabela 6: Parâmetros gerados pelo modelo sazonal baseado em dados de primavera-verão.

\begin{tabular}{|lcccccc|}
\hline Grupo trófico & $\mathrm{NT} *$ & $\mathrm{~B}$ & $\mathrm{P} / \mathrm{B}$ & $\mathrm{Q} / \mathrm{B}$ & $\mathrm{EE}$ & $\mathrm{P} / \mathrm{Q}^{*}$ \\
\hline Lophius gastrophysus & 4,6 & 0,11 & 0,20 & 1,40 & $0,00^{*}$ & 0,14 \\
\hline Lulas & 4,0 & 3,52 & 1,29 & 2,60 & $0,73^{*}$ & 0,50 \\
\hline Piscívoros pelágicos & 4,5 & 1,80 & 0,90 & 1,33 & $0,02^{*}$ & 0,68 \\
\hline Espada & 4,2 & 0,75 & 0,48 & 1,64 & $0,71^{*}$ & 0,29 \\
\hline Merluza & 4,1 & $0,27^{*}$ & 0,70 & 1,97 & 0,90 & 0,35 \\
\hline Pescadas & 3,9 & $0,15^{*}$ & 0,87 & 3,60 & 0,85 & 0,24 \\
\hline Piscívoros bentônicos & 4,5 & $0,03^{*}$ & 0,92 & 2,00 & 0,80 & 0,46 \\
\hline $\begin{array}{l}\text { Comedores de invertebrados } \\
\text { bentônicos e peixes }\end{array}$ & 3,6 & 0,29 & 0,47 & 2,25 & $0,56^{*}$ & 0,21 \\
\hline Raneya brasiliensis & 3,4 & 0,05 & 0,48 & 2,53 & $0,74^{*}$ & 0,19 \\
\hline Bentófagos I & 3,2 & $1,0 *$ & 0,25 & 1,33 & 0,95 & 0,19 \\
\hline Bentófagos II & 3,4 & 0,41 & 0,77 & 2,53 & $0,67^{*}$ & 0,31 \\
\hline Zooplanctófagos & 3,3 & 1,53 & 1,87 & 9,20 & $0,98^{*}$ & 0,20 \\
\hline Outros pequenos pelágicos & 3,7 & 3,17 & 2,13 & 7,33 & $0,34^{*}$ & 0,29 \\
\hline Sardinha & 2,4 & $6,19 *$ & 2,40 & 13,53 & 0,95 & 0,18 \\
\hline Zooplâncton II & 2,8 & $3,04^{*}$ & 17,15 & 49,00 & 0,70 & 0,35 \\
\hline Zooplâncton I & 2,1 & $7,0^{*}$ & 24,00 & 40,00 & 0,80 & 0,60 \\
\hline Camarão & 2,0 & $14,59 *$ & 3,47 & 22,20 & 0,80 & 0,16 \\
\hline Bentos carnívoro & 3,2 & 12,36 & 3,73 & 12,40 & $0,52^{*}$ & 0,30 \\
\hline Bentos depositívoro/detritívoro & 2,0 & 45,00 & 2,20 & 18,20 & $0,94^{*}$ & 0,12 \\
\hline Fitoplâncton & 1,0 & 257,33 & 77,13 & 0,00 & $0,02^{*}$ & \\
\hline Detritus & 1,0 & 41,68 & & & $0,06^{*}$ & \\
\hline
\end{tabular}

B=Biomassa; $P / B=$ produção por biomassa; $Q / B=$ consumo por biomassa; $E E=$ eficiência ecotrófica; *valores gerados pelo modelo

Quanto à inclusão do compartimento Zooplancton II, ela foi baseada na suposição de que esse grupo pudesse alterar a estrutura trófica do sistema por apresentar características ecológicas bastante diferentes dos copépodas e copepoditos que são os principais representantes do grupo Zooplâncton I (Lopes², Comunicação Pessoal).

\footnotetext{
${ }^{2}$ Lopes, R.M. Dr. Professor do Instituto Oceanográfico da Universidade de São Paulo.
} 
A ocorrência do grupo que inclui as salpas (Zooplancton II) durante períodos de intensa ressurgência foi também registrada por Rocha (1998) e Katsuragawa et al. (1993) em Ubatuba, SP. No entanto, a inclusão desse grupo não resultou em diferenças acentuadas na trama trófica dos modelos sazonais.

Pode-se supor que a presença desse grupo não interferiu nas relações tróficas do sistema, devido ao fato de seus componentes não constituírem presas importantes nas dietas dos outros consumidores. Segundo Pomeroy e Deibel (1980), as salpas atuam expressivamente na exportação rápida de matéria orgânica da região pelágica para o fundo através de pelotas fecais, o que pode incrementar de maneira rápida a cadeia detritívora. Esse grupo pode ainda causar grande impacto na predação de organismos zooplanctônicos menores, no entanto, as informações de produção e consumo das espécies zooplantônicas são insuficientes para finalizar uma conclusão sobre a participação efetiva das salpas no funcionamento do ecossistema de Cabo Frio.

Outra característica importante evidenciada nos modelos sazonais foi a pouca variação da composição das dietas dos grupos tróficos. As espécies componentes dos grupos tróficos apresentam diferenças sazonais nas composições alimentares, porém, ao construir as matrizes das dietas, essas variações foram amenizadas por se tratarem de variações entre presas pertencentes ao mesmo 
compartimento trófico do modelo, não ocorrendo variação entre eles, especialmente nos peixes. Essa constatação de que a variação sazonal na composição da dieta não implica, necessariamente, na diferença de posição trófica foi registrada por Vera (2006), em estudo da dieta do peixe Raneya brasiliensis do sistema de Cabo Frio.

Como esperado, os atributos ecológicos gerados pelo Ecopath nos modelos sazonais apresentaram algumas diferenças entre aqueles que consideram as biomassas e os totais de fluxos e diferenças menores nos parâmetros que consideram os níveis tróficos e as relações interespecíficas (Tabela 7), sendo as biomassas bem mais elevadas durante o verão.

A soma dos consumos, respiração total e soma dos fluxos para o detrito, por exemplo, foi maior no modelo de primavera-verão devido à maior biomassa de todos os compartimentos do modelo. No entanto, o índice de predação e a eficiência de transferência mantiveram-se semelhantes nos dois modelos.

Considerando-se as semelhanças dos dois modelos sazonais, propõe-se que um modelo médio anual poderá representar adequadamente o as interações tróficas desse ecossistema. Levanta-se a suposição de que dados sazonais de desembarque pesqueiro possam contribuir para a construção e análise mais aprofundada dos modelos sazonais. 
Tabela 7: Parâmetros ecológicos gerados pelo modelo com base em dados sazonais.

\begin{tabular}{|c|c|c|c|}
\hline Parâmetros & $\begin{array}{l}\text { Primavera- } \\
\text { verão }\end{array}$ & $\begin{array}{l}\text { Outono- } \\
\text { inverno }\end{array}$ & Unidade \\
\hline Soma dos consumos & 3029,15 & 534,91 & $\mathrm{~g} / \mathrm{m}^{2} / \mathrm{ano} / 2$ \\
\hline Total de Exportação & 17953,14 & 914,32 & $\mathrm{~g} / \mathrm{m}^{2} / \mathrm{ano} / 2$ \\
\hline Respiração total & 1902,498 & 327,06 & $\mathrm{~g} / \mathrm{m}^{2} / \mathrm{ano} / 2$ \\
\hline Total de fluxo para o detrito & 19083,56 & 1278,19 & $\mathrm{~g} / \mathrm{m}^{2} / \mathrm{ano} / 2$ \\
\hline Throughput & 41968,36 & 3054,47 & $\mathrm{~g} / \mathrm{m}^{2} / \mathrm{ano} / 2$ \\
\hline Produção total & 20369,8 & 1339,78 & \\
\hline Produção primária total & 19848,98 & 1238,92 & $\mathrm{~g} / \mathrm{m}^{2} / \mathrm{ano} / 2$ \\
\hline Prod. Prim./Respiração & 19083,56 & 1278,19 & \\
\hline Prod.Prim./Biomassa total & 51,19064 & 15,81 & \\
\hline Biomassa/Throughput & 0,0092 & 0,03 & $\mathrm{~g} / \mathrm{m}^{2}$ \\
\hline $\begin{array}{l}\text { Total biomassa (excluindo } \\
\text { detrito) }\end{array}$ & 387,7462 & 78,39 & $\mathrm{~g} / \mathrm{m}^{2} / \mathrm{ano} / 2$ \\
\hline Índice de conectância & 0,2732498 & 0,30 & \\
\hline Índice de onivoria & 0,247531 & 0,29 & \\
\hline Eficiência de transferência & 16 & 16,30 & $\%$ \\
\hline Índice de Predação & 2,82 & 2,58 & \\
\hline Índice de Finn & 0,99 & 0,77 & $\%$ \\
\hline Ascendencia (\%) & 61,9 & 48,3 & $\%$ \\
\hline Overhead (\%) & 38,1 & 51,7 & $\%$ \\
\hline Comprimento médio das vias & 6,42 & 8,53 & \\
\hline
\end{tabular}




\section{V.2 Modelo Médio Anual}

Resultados do modelo anual expressam uma condição média do sistema de ressurgência de Cabo Frio, que foi considerado bastante consistente, apesar da sazonalidade associada ao fenômeno da ressurgência Suas características e atributos serão discutidos a seguir.

\section{V.2.1 NÍVEL TRÓFICO}

A organização de um ecossistema é descrita através dos passos entre os níveis tróficos (Gerking, 1994), cada um deles representando uma etapa no caminho do fluxo da matéria ao longo da trama do ecossistema. O nível trófico (NT) gerado pelo Ecopath é expresso em valor fracional, como sugerido por Odum e Heald (1975), diferenciandose do conceito de nível trófico proposto por Lindeman (1942), por ser calculado a partir do nível trófico das presas, ponderando-se proporções de cada presa na sua dieta. Seu cálculo no Ecopath é baseado na matriz de dieta que foi elaborada a partir de dados oriundos de análises de conteúdos estomacais das espécies de cada compartimento do modelo. Dessa maneira, a matriz de dieta é uma das principais informações para a construção de modelos tróficos, visto que é a base para o balanceamento do modelo. 
O NT dos compartimentos do modelo anual de Cabo Frio, em geral, foi similar ao NT isotópico calculado para os grupos tróficos equivalentes por Soares et al. (em preparação) e Corbisier, 2006 (Tabela 8). Essa similaridade é uma validação expressiva do NT, considerando-se que os conteúdos estomacais, informação utilizada como base para a elaboração da matriz de dieta do modelo, fornecem informações pontuais e os dados de isótopos estáveis uma integração temporal da dieta (de semanas no caso de músculo) (Valiela, 1995). Resultados semelhantes foram obtidos nos modelos Ecopath de sistemas de altas latitudes, como Prince Willian Sound, no Alaska e do norte da Noruega (Kline e Pauly, 1998; Mathisen e Sands, 1999). Concluiu-se que essa validação do NT confere consistência às estatísticas geradas.

Os grupos de peixes pelágicos como a "sardinha", os "zooplanctófagos" e "outros pequenos pelágicos" apresentaram NT baixo (2-3), indicando dietas compostas por fitoplâncton e zooplâncton. O nível trófico entre 2 e 3 dos organismos bentônicos coincidiu com os valores do modelo do ecossistema de Ubatuba (Rocha,1998) e da plataforma sudeste do Brasil (Gasalla, 2004), indicando uma dieta baseada em detrito e/ou de presas comedoras de detrito. Foi também observado que $57 \%$ da biomassa total dos organismos do ecossistema de Cabo Frio apresentaram nível trófico entre 2 e 3, característica comumente registrada em regiões de ressurgência (Jarre-Teichmann, 
1998; Shannon et al., 2003; Moloney et al., 2005; Coll et al., 2006; Medina et al., 2007).

Tabela 8: Comparação entre o nível trófico (NT) isotópico e o calculado pelo modelo.

\begin{tabular}{|lcc|}
\hline \multicolumn{1}{|c|}{ Grupo trófico } & NT \\
\hline Lophius gastrophysus & Ecopath & Isótopos \\
\hline Lulas & 4,6 & 4,7 \\
\hline Piscívoros pelágicos & 3,9 & 3,8 \\
\hline Espada & 4,5 & 4,8 \\
\hline Merluza & 4,1 & 5 \\
\hline Pescadas & 4,1 & 3,9 \\
\hline Piscívoros bentônicos & 3,9 & 4,6 \\
\hline Comedores de invertebrados & 4,5 & 4,6 \\
\hline bentônicos e peixes & 3,7 & 4,4 \\
\hline Raneya brasiliensis & 3,4 & 4,1 \\
\hline Bentófagos I & 3,3 & 4,5 \\
\hline Bentófagos II & 3,4 & 4,5 \\
\hline Zooplanctófagos & 3,3 & 4,2 \\
\hline Outros pequenos pelágicos & 3,8 & 4,5 \\
\hline Sardinha & 2,3 & 4,2 \\
\hline Zooplâncton II & 2,7 & 2,6 \\
\hline Zooplâncton I & 2,1 & 2,2 \\
\hline Camarão & 2,0 & 3,6 \\
\hline Bentos carnívoro & 3,3 & 1,4 \\
\hline Bentos depositívoro/detritívoro & 2,0 & \\
\hline Fitoplâncton & 1,0 & 2,4 \\
\hline Detrito & & \\
\hline
\end{tabular}




\section{V.2.2 PARÁmetros DO MODELO}

Na Tabela 9 estão apresentados os parâmetros do modelo anual. Entre eles cabe ressaltar primeiramente as estimativas das biomassas, como por exemplo, a biomassa do grupo trófico "Espada", cuja pesca artesanal é importante na região (Magro, 2006); como esperado, a biomassa estimada pelo modelo para esse grupo foi maior que a encontrada por Gasalla et al. (2007) no modelo de plataforma e talude da costa sudeste brasileira. Essa biomassa pode ainda ser maior, visto que o Ecopath calcula biomassa mínima para equilíbrio do modelo, e os dados de pesca que são fundamentais para esse cálculo, e provavelmente estão subestimados. Segundo Azevedo (2004), a pesca de espada vem aumentando substancialmente em substituição à de anchova em Cabo Frio nessa última década, característica muito comum nas pescarias multi-específicas em que a redução dos estoques das espécies-alvos resulta na intensificação do esforço sob outros recursos (Hilborn e Walters, 1992). Dessa maneira a exploração do peixe espada como novo alvo de pescarias no ecossistema de Cabo Frio merece atenção e requer estudos específicos.

As biomassas do grupo "sardinha" e dos grupos "Zooplâncton (I e II)" foram também maiores do que as encontradas por Rocha (1998) no modelo do sistema de Ubatuba. Essas diferenças poderiam ainda ser maiores, se considerarmos que os valores utilizados no modelo deste 
trabalho estiverem subestimados, visto que a região sustenta grande parte da produção pesqueira do estado do Rio de Janeiro (PROZEE, 2005) e há grande possibilidade de que dados de captura da pesca informal não tenham sido incluídos nas estatísticas oficiais (Gasalla e Tomás, 1998).

Um ponto que merece menção é a biomassa fitoplantônica que apresentou a mesma característica do modelo de verão já discutido. Neste trabalho foi considerado como produtor apenas o fitoplâncton, que segundo Gunter-Soares (2006) é o grupo como a maior fonte de matéria orgânica particulada a ser transferida ao longo da cadeia alimentar de Cabo Frio, com pouca ou nenhuma participação do bacterioplâncton nessas relações. É um padrão diferente do encontrado por Rocha (1998) no sistema de Ubatuba em que o bacterioplâncton apresentou papel importante nas relações tróficas na base da cadeia. 
Tabela 9: Parâmetros gerados pelo modelo médio anual. Entre parênteses dados gerados pelo modelo.

\begin{tabular}{|c|c|c|c|c|c|}
\hline Grupo trófico & B & $P / B$ & $Q / B$ & EE & $(P B / Q B)$ \\
\hline 1 Lophius gastrophysus & 0,17 & 0,3 & 2,1 & (0) & 0,14 \\
\hline 2 Lulas & 3,76 & 1,95 & 3,9 & $(0,79)$ & 0,5 \\
\hline 3 Piscívoros pelágicos & 1,7 & 1,35 & 2 & $(0,06)$ & 0,67 \\
\hline $4 \quad$ Espada & $(1,8)$ & 1,28 & 2,46 & 0,7 & 0,52 \\
\hline $5 \quad$ Merluza & $(0,11)$ & 0,95 & 2,96 & 0,96 & 0,32 \\
\hline 6 Pescadas & 0,19 & 1,23 & 5,4 & $(0,83)$ & 0,22 \\
\hline 7 Piscívoros bentônicos & 0,36 & 1,38 & 3 & $(0,64)$ & 0,46 \\
\hline Comedores de invertebrad & & & & & \\
\hline 8 bentônicos e peixes & 0,43 & 0,8 & 3,38 & $(0,69)$ & 0,23 \\
\hline 9 Raneya brasiliensis & 0,08 & 1,5 & 3,8 & $(0,95)$ & 0,39 \\
\hline 10 Bentófagos I & 1,5 & 1,16 & 2 & $(0,43)$ & 0,58 \\
\hline 11 Bentófagos II & 0,6 & 1,16 & 3,8 & $(0,70)$ & 0,30 \\
\hline 12 Zooplanctívoros & 2,3 & 2,8 & 13,8 & $(0,52)$ & 0,20 \\
\hline 13 Outros pequenos pelágicos & 2,01 & 3,19 & 11 & $(0,58)$ & 0,29 \\
\hline 14 Sardinha & $(5,98)$ & 3,6 & 20,3 & 0,9 & 0,17 \\
\hline 15 Zooplâncton II & $(22,5)$ & 100 & 248 & 0,6 & 0,40 \\
\hline 16 Zooplâncton I & $(31,4)$ & 104 & 240 & 0,8 & 0,43 \\
\hline 17 Camarão & $(17,9)$ & 5,2 & 33,3 & 0,8 & 0,15 \\
\hline 18 Bentos carnívoro & 18,54 & 5,59 & 15 & $(0,94)$ & 0,37 \\
\hline 19 Bentos depositívoro /detritívoro & 68,0 & 1,35 & 15 & $(0,79)$ & 0,09 \\
\hline 20 Fitoplâncton & 205,8 & 115,7 & 0 & $(0,03)$ & \\
\hline 21 Detrito & 66,7 & & & $(0,07)$ & \\
\hline
\end{tabular}

B=Biomassa; $\mathrm{P} / \mathrm{B}=$ produção por biomassa; $\mathrm{Q} / \mathrm{B}=$ consumo por biomassa; $\mathrm{EE}=$ eficiência ecotrófica. 


\section{V.2.3 ATRIBUTOS ECOLÓGICOS DO ECOSSISTEMA}

Odum (1971) sugere 23 atributos que podem ser utilizados para caracterizar e avaliar o estado de desenvolvimento de um ecossistema. Desses, Christensen e Pauly (1998) selecionaram 11 que descrevessem de maneira adequada as características dos ecossistemas marinhos e pudessem indicar os padrões necessários para que sejam desenvolvidos planos de manejo para conservação e exploração sustentável desses ecossistemas. Esses atributos juntamente com outras estatísticas do sistema estão sumariados na Tabela 10.

Os atributos relacionados à produtividade e consumo tendem ao equilíbrio, ou seja, tudo o que for produzido será utilizado para a manutenção da biomassa. Assim, a análise dos parâmetros de Produção primária/Respiração (PP/R) e Produção primária/ Biomassa total (PP/B) fornecidos pelo Ecopath são utilizados para avaliar o grau de maturidade do ecossistema como sugerido por Odum (1971), que propôs que nos primeiros estágios de maturidade a produção é muito maior que a total de respiração (PP/R >1).

Para esses dois parâmetros os valores encontrados no modelo anual foram bastante altos, indicando situação de desenvolvimento desse ecossistema. Sistemas de ressurgência, de uma maneira geral, apresentam-se como sistemas em desenvolvimento, com altos valores 
dos parâmetros que relacionam a Produção primária e consumo (JarreTeichmann e Pauly, 1993; Medina et al., 2007; Moloney et al., 2005).

Tabela 10: Parâmetros ecológicos gerados pelo modelo com base em dados médios anuais.

\begin{tabular}{|c|c|c|}
\hline Soma dos consumos & 4632,4 & $\mathrm{~g} / \mathrm{m}^{2} / \mathrm{ano}$ \\
\hline Total de Exportação & 1924,21 & $\mathrm{~g} / \mathrm{m}^{2} / \mathrm{ano}$ \\
\hline Respiração total & 1556,57 & $\mathrm{~g} / \mathrm{m}^{2} / \mathrm{ano}$ \\
\hline Total de fluxo para o detrito & 3518,9 & $\mathrm{~g} / \mathrm{m}^{2} / \mathrm{ano}$ \\
\hline Throughput & 11632,07 & $\mathrm{~g} / \mathrm{m}^{2} / \mathrm{ano}$ \\
\hline Produção total & 5579,86 & \\
\hline Produção primária total & 3430,51 & $\mathrm{~g} / \mathrm{m}^{2} / \mathrm{ano}$ \\
\hline Prod. Prim./Respiração & 3518,9 & \\
\hline Prod.Prim./Biomassa total & 15,74 & \\
\hline Biomassa/Throughput & 0,02 & $\mathrm{~g} / \mathrm{m}^{2}$ \\
\hline Total biomassa (excluindo detritus) & 218,02 & $\mathrm{~g} / \mathrm{m}^{2} / \mathrm{ano}$ \\
\hline Índice de conectância & 0,28 & \\
\hline Índice de onivoria & 0,28 & \\
\hline Eficiência de transferência & 22,8 & $\%$ \\
\hline Índice de Predação & 5,52 & $\%$ excluindo detrito \\
\hline Índice de Finn & 6,64 & $\%$ total \\
\hline Ascendencia (\%) & 34,9 & $\%$ \\
\hline Overhead (\%) & 65,1 & $\%$ \\
\hline Comp. Médio das vias & 9,1 & \\
\hline
\end{tabular}


Outro atributo é a eficiência de transferência, que é estimada entre grupos tróficos de acordo com Lindeman (1942). As eficiências de transferência são geralmente maiores no início da cadeia alimentar (fotorreceptora) quando comparada com os níveis tróficos superiores, e estão relacionadas às características intrínsecas dos organismos (Odum, 1988; Christensen e Pauly, 1993).

O Ecopath calcula as eficiências de transferência como sendo a fração de fluxos totais que cabe a cada nível trófico (produção) que é exportado ou transferido a outro nível trófico através do consumo. Baseado no sistema e nas eficiências de transferência entre níveis tróficos, Christensen e Pauly (1993) estimaram valores médios de 10\% de eficiência de transferência para diversos ecossistemas. Ecossistemas de ressurgência são de uma maneira geral pouco eficientes em relação à transferência, Jarre-Teichman e Christensen (1998) estimaram um valor médio de $5 \%$ para quatro sistemas de ressurgência. Essa aparente ineficiência na transferência está relacionada às características intrínsecas dos produtores e à organização trófica dos sistemas que apresentam alta exportação de carbono, fator típico dos episódios de rápida floração do fitoplâncton (Berger et al., 1989).

No sistema de Cabo Frio o valor estimado foi de $23,7 \%$. Uma das hipóteses é de que esse alto valor da eficiência seja decorrente da fragilidade dos dados do Zooplâncton (I e II), um dos principais grupos tróficos desse sistema, cujos valores de $\mathrm{P} / \mathrm{B}, \mathrm{Q} / \mathrm{B}$ e biomassa poderiam 
não expressar a realidade, visto que é um grupo bastante diversificado com diferentes taxas de produção e consumo (Christensen', comunicação pessoal). Estudos específicos de produção secundária e consumo desses grupos poderiam fornecer dados para estimativas mais precisas desse parâmetro no sistema de Cabo Frio. Por outro lado, a possibilidade desse sistema possuir alta eficiência não pode ser descartada, considerando suas características peculiares e área menor que outros sistemas de ressurgência já modelados como o do Chile, Peru, Venezuela e Namíbia (Jarre-Teichmann e Pauly, 1993; Medina et al., 2007; Moloney et al., 2005).

A somatória das vias do fluxo (comprimento médio das vias) expressa, juntamente com outras estatísticas do ecossistema, o grau de maturidade do ecossistema, isto é, quanto maior o tamanho maior é a reciclagem no ecossistema. O valor de 9,1 indicou pouca reciclagem de matéria, situação típica de estágio de desenvolvimento do ecossistema. Outro indicador de reciclagem, o índice de Finn (\%), que mede a biomassa total reciclada no sistema, foi baixo $(1,14 \%)$ (Tabela 5), caracterizando, novamente, um sistema em desenvolvimento, pois segundo Odum (1986), ambientes maduros tendem a reciclar grande parte da biomassa.

Entre as propriedades chamadas de emergentes, resultantes dos processos autoreguladores do ecossistema, que descrevem sua

\footnotetext{
${ }^{3}$ Christensen, V. PhD professor do Fishery Centre na University of British Columbia, Vancouver, Canadá
} 
maturidade, o Ecopath fornece os seguintes atributos: Ascendência e Overhead. Essas propriedades segundo Laszlo (1978) apud Muller (1992) não podem ser descritas como a soma das propriedades e comportamentos de seus componentes, se estes forem investigados isoladamente. Nos níveis superiores, propriedades emergentes são caracterizadas como propriedades adicionais indo além da simples soma das unidades constituintes (propriedades coletivas).

A ascendência pode ser entendida como a quantidade de informação trocada no sistema, o que minimiza a incerteza da localização de uma unidade de energia em um tempo seguinte (Angelini, 2002). Segundo Ulanowicz (1986), os sistemas evolvem tanto quanto aperfeiçoam a ascendência, porém esse desenvolvimento tem um limite que é a capacidade de desenvolvimento. A diferença entre a ascendência e a capacidade de desenvolvimento é o chamado Overhead. Segundo Angelini (op. cit.), o overhead é ainda uma medida do grau de desorganização de um sistema, inversamente à ascendência que é o grau de organização. Em entrevista concedida a Hoffmann (2001), Ulanowicz ressalta a importância do overhead para a persistência de longo termo do sistema, e afirma que sistemas com alto grau de organização, com ascendência alta, apresentam uma coesão interna tamanha que o torna altamente vulnerável às perturbações externas. 
Os valores calculados para a ascendência e o overhead do sistema de Cabo Frio (Tabela 9) indicaram que esse ecossistema ainda tem capacidade de desenvolvimento e, portanto de resistir a perturbações (resiliência). Os resultados obtidos referendam a literatura, que registra que a resiliência de sistemas em desenvolvimentos é muito maior que a sistemas maduros (Odum, 1986).

A conectância e o índice de onivoria do sistema são índices que descrevem as relações tróficas entre as espécies. A conectância, que expressa número de ligações entre os componentes (Allen e Starr, 1982), apresentou os valores (Conectância >0) em Cabo Frio que indicaram alta diversidade de itens alimentares na dieta dos predadores. Valores semelhantes foram encontrados por Rocha (1998), Gasalla et al. (2007), e Rocha et al. (2008) para sistemas da costa sudeste brasileira.

A diversidade na composição da dieta dos predadores está relacionada à riqueza e diversidade de espécies no local, sendo essa uma das principais características dos ecossistemas de regiões tropicais e subtropicais. Segundo Lowe-McConel (1999), ecossistemas tropicais são caracteristicamente diversificados e possuem interações muito complexas quando comparados aos sistemas temperados. Embora seja uma região de ressurgência e apresente variação sazonal nas condições oceanográficas, o sistema de Cabo Frio, nesse aspecto, se assemelha aos demais sistemas de regiões tropicais. 
O índice de onivoria reflete a fração de espécies que se alimenta em vários níveis tróficos (Williams e Martinez, 2004), caracterizando a complexidade da teia trófica. Segundo McCann e Hastings (1997), altos valores de onivoria poderiam garantir a estabilidade do ecossistema frente à remoção de espécies. Cabo Frio apresentou índice de onivoria maior que zero, que é um valor semelhante aos encontrados nos sistemas da costa sudeste brasileira (Rocha, 1998; Gasalla et al., 2007), indicando alta estabilidade desse sistema.

O diagrama de fluxo gerado pelo Ecopath ilustra de maneira simplificada as relações entre os grupos tróficos do ecossistema, dando uma idéia da complexidade dessa estrutura. Nesse desenho é possível quantificar, através da espessura das linhas, a transferência de biomassa entre os grupos e através do tamanho dos círculos as biomassas dos compartimentos (Figura 6).

A complexidade das relações entre grupos de presa-predador pode ser mais bem visualizada na trama do local, eliminando-se a proporção tanto do tamanho dos compartimentos quanto da espessura das linhas e incluindo-se os valores de biomassa (Figura 7). Tal complexidade é típica de sistemas tropicais, constituída por grande número de grupos tróficos como resultado da grande diversidade de espécies nessas regiões, proporcionando uma alta quantidade de vias nas inter-relações desses grupos (Longhurst e Pauly, 2007). O ecossistema tropical de Serra Leoa, por exemplo, apresentou 160 
espécies de peixes que foram agrupadas em 10 compartimentos tróficos.

À semelhança desse sistema, o grupo de "comedores de bentos e peixes" agrupou a maior número de espécies em Cabo Frio juntamente com grupo Bentófagos II (comedores de poliquetas e ofiuróides). Essa característica indica a grande diversidade e participação da cadeia bentônica, ou seja, sustentada principalmente pelo detrito. 
5

4

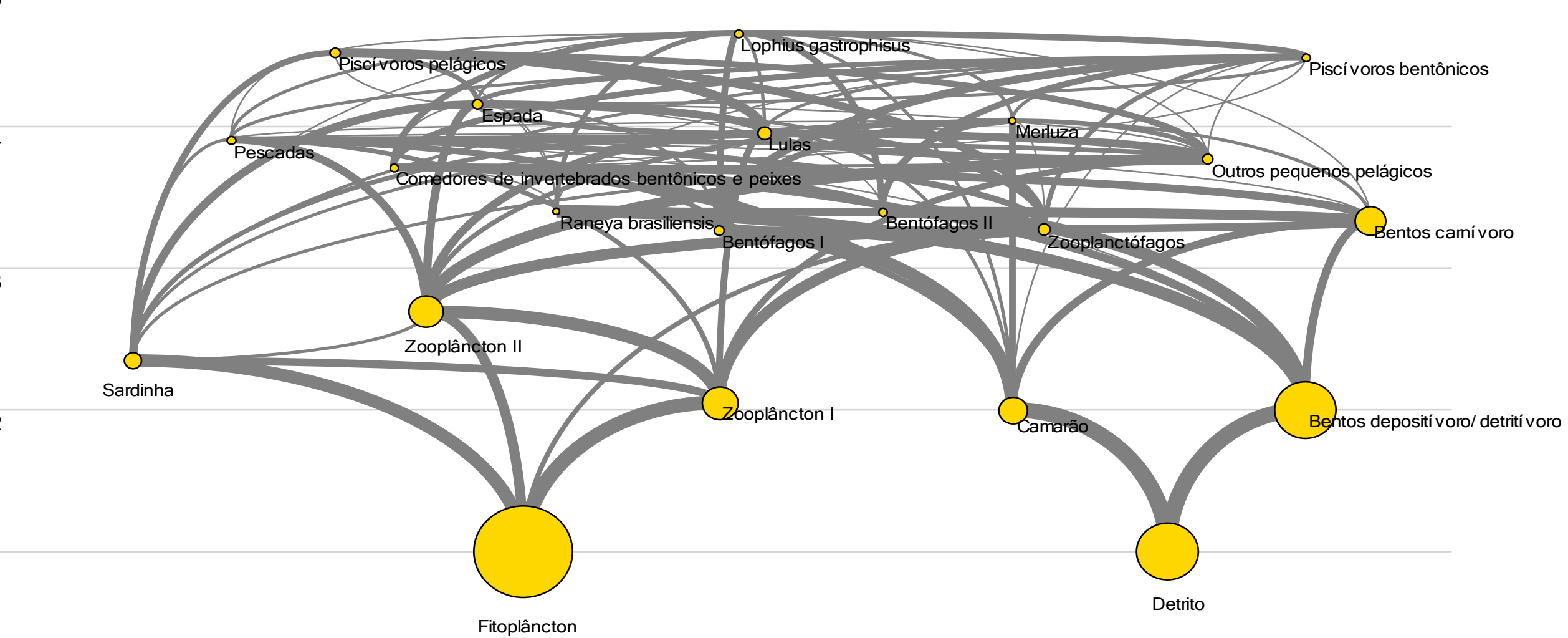

Figura 6: Diagrama de fluxo baseado em dados do modelo anual. O tamanho dos compartimentos é proporcional à biomassa e a espessura das linhas quantifica os fluxos (NT= nível trófico). 


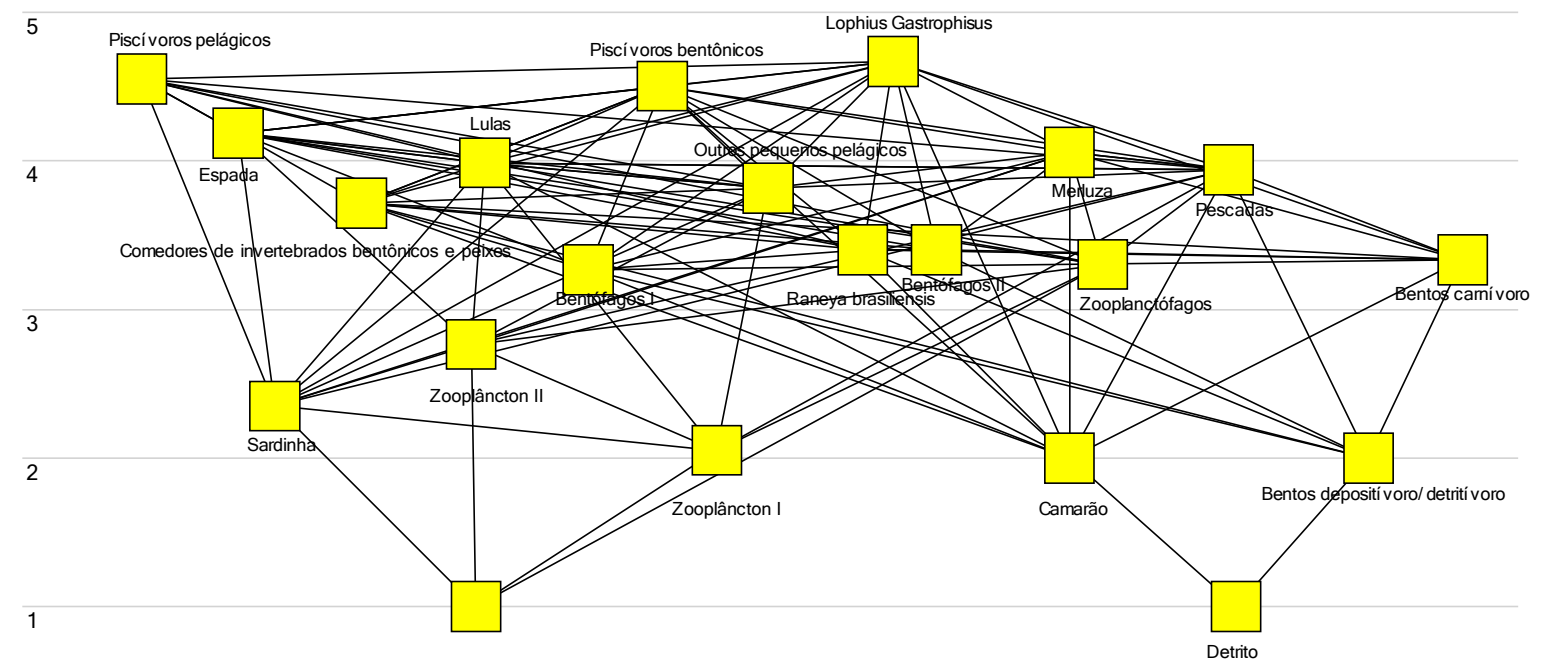

Fitoplâncton

Figura 7: Diagrama de fluxo simplificado do sistema de Cabo Frio.

Nas interrelações tróficas, um organismo, como presa causa impacto positivo, e como predador, negativo. Através dos resultados da análise clássica econômica de entrada-saída de fluxo (Leontief, 1951) associada à análise de redes ecológicas é possível identificar impactos (positivos e negativos), através de interações diretas e indiretas (incluindo competição) de todos os grupos analisados no sistema através do Ecopath (Ulanowicz e Puccia, 1990).

Os resultados do impacto podem ser visualizados na Figura 8, "matriz de impacto trófico misto" que representa valores relativos, no qual determinado grupo (coluna da direita) exerce impacto em todo o sistema modelado (coluna da esquerda). Embora os valores de impacto 
sejam relativos, eles são comparáveis entre si. O grupo "Espada" se destacou pelo alto impacto negativo causado ao grupo "lulas" e "piscívoros bentônicos". O grupo "Iulas", por outro lado, imprimiu alto impacto positivo no grupo de "piscívoros pelágicos".

A análise da matriz de impactos serve para identificar gruposchave na cadeia alimentar e possível necessidade de informações sobre eles. De qualquer forma, a análise dos impactos tróficos mistos, pode ser visto como uma análise simples de sensibilidade do modelo, como sugerido por Majkowsky (1982). A identificação desses impactos pode auxiliar na antecipação de problemas da pesca excessiva, indicando os efeitos diretos e indiretos de alterações nas biomassas de grupos pescados na região, que acarretariam impactos bruscos em diversos componentes do ecossistema. Essas informações podem subsidiar planos de manejos para as pescarias, especialmente as multiespecíficas. 
Impacted group

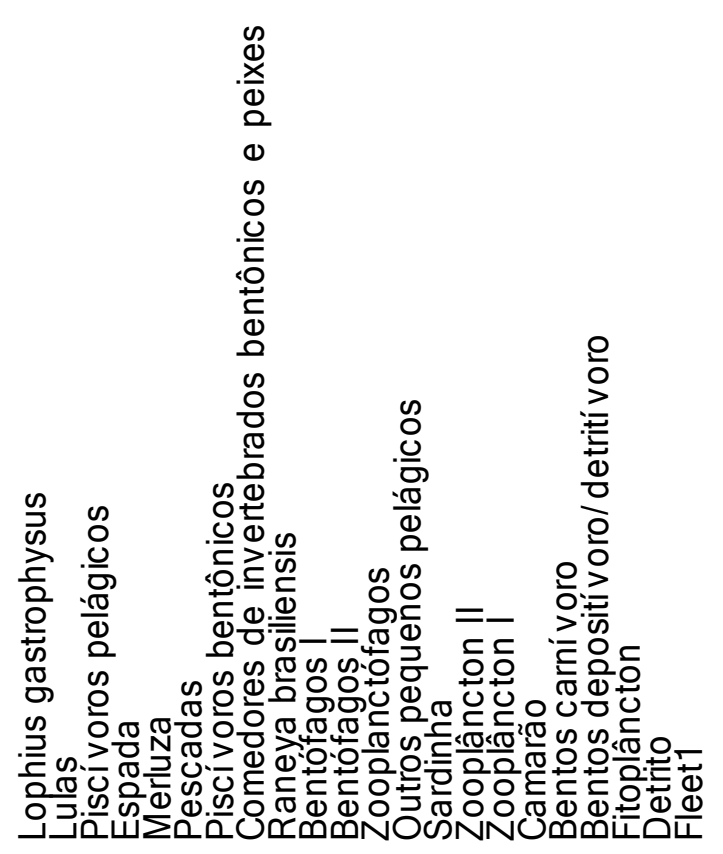

Positive
Negative

Lophius gastrophysus

Lulas

Piscívoros pelágicos

Espada

Merluza

Pescadas

Piscívoros bentônicos

Comedores de invertebrados bentônicos e peixes Raneya brasiliensis

Bentófagos I

Bentófagos II

Zooplanctófagos

Outros pequenos pelágicos

Sardinha

Zooplâncton II

Zooplâncton I

Camarão

Bentos camí voro

Bentos depositívoro/ detritívoro

Fitoplâncton

Detnito

Fleet1 


\section{V.2.4 SIMULAÇÕES DINÂMICAS DOS EFEITOS DA VARIABILIDADE OCEÂNICA}

A simulação realizada é apresentada como um exercício, pois para uma simulação mais robusta são necessárias séries históricas de dados.

Na Figura 9 estão representadas as velocidades de resposta das variações da biomassa dos diferentes grupos tróficos em relação à variação na biomassa dos produtores da cadeia trófica. A variabilidade das condições oceanográficas da região está relacionada à intrusão da ACAS na plataforma continental, que traz à zona eufótica grande quantidade de nutrientes, acarretando o aumento da biomassa fitoplanctônica e da produção primária, disponibilizando maior quantidade de alimento para os níveis tróficos subsequentes (Pires-Vanin \& Matsuura, 1993). Esse aumento da produtividade traz respostas em diferentes velocidades de acordo com o as dinâmicas populacionais dos componentes de cada compartimento trófico.

Os grupos diretamente relacionados ao fitoplâncton apresentaram respostas mais rápidas, como era de se esperar. E ressalta-se principalmente a forte resposta dos grupos de bentos à variação na produção primária, indicando que a intrusão da ACAS pode alterar tanto a cadeia pelágica como a cadeia de fundo.

Esse exercício mostra que os dados de temperatura da superfície do mar (TSS) podem ser adequadamente utilizados como "forçante" 
ambiental para incluir o fenômeno sazonal da ressurgência em futuras simulações de variações nas biomassas. Pode-se assim, construir cenários de pesca partindo do modelo médio anual e levando em consideração o fenômeno da ressurgência costeira em Cabo Frio.

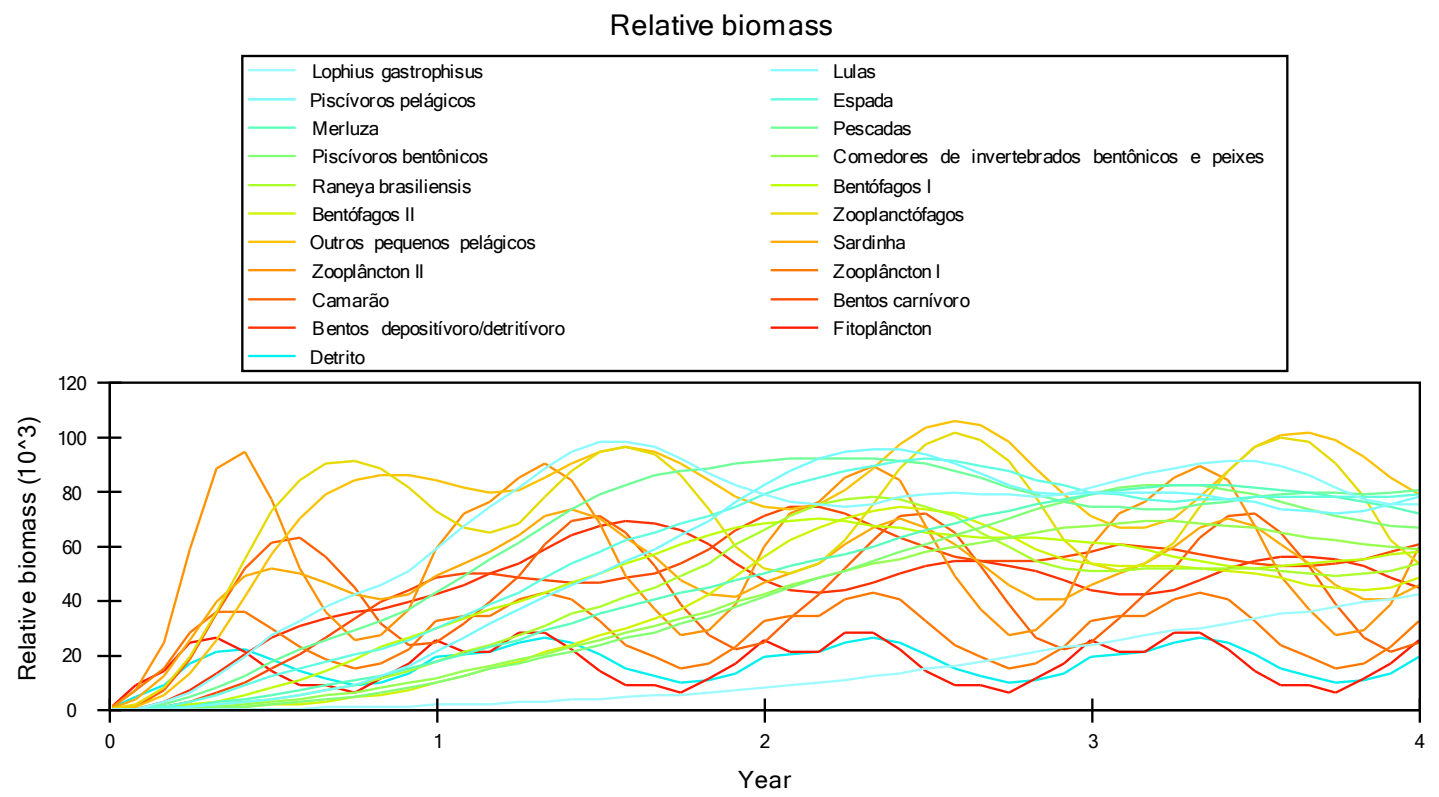

Figura 9: Simulação da variação das biomassas dos grupos tróficos em resposta a variação do fitoplâncton considerando vulnerabilidade = 1 para os predadores. 


\section{CONCLUSÕES E CONSIDERAÇÕES FINAIS}

De acordo com os resultados obtidos e a discussão apresentada, o ecossistema de ressurgência de Cabo Frio no estado do Rio de Janeiro possui características de um sistema em desenvolvimento, com certa desorganização dos seus processos e alta resiliência. Sua complexidade em relação à trama trófica, com alto grau de conectância entre seus compartimentos e alto índice de onivoria torna esse ecossistema estável e, portanto passivel de recuperação frente aos distúrbios ambientais. Conclui-se também que um modelo médio anual é capaz de representar de maneira adequada o ecossistema de Cabo Frio, podendo servir de base para um manejo de atividades exploratórias.

Fica claro que o sistema de Cabo Frio é um ecossistema estável e resiliente, capaz de resistir a perturbações, remoção de espécies, e sustentar atividades pesqueiras, no entanto o modelo representa um momento inicial, e não leva em consideração a situação atual da pesca na região. Para o manejo dessa atividade, deve-se partir do modelo gerado, incluir dados atualizados de mortalidade por pesca e então simular cenários que permitam estabelecer limites sustentáveis de exploração, podendo estes indicar a necessidade de redução ou possibilidade de aumento dos atuais esforços pesqueiros.

Dessa maneira a utilização sistemática do Ecopath, com inclusão de parâmetros atualizados e novas informações ecológicas dos grupos 
tróficos, pode fornecer bases para modelagem dinâmica do ecossistema de ressurgência de Cabo Frio.

A alta produtividade primária encontrada nesse trabalho indica uma capacidade de suportar grandes biomassas de consumidores, no entanto existem diversos fatores atuantes nessa relação, o que pode produzir um resultado indireto diferente do esperado. É nesse sentido que se ressalta a importância dos estudos tróficos e de dinâmica populacional dos organismos zooplanctônicos, bem como estudos das taxas produção e consumo desses organismos que permitam a compreensão do ecossistema como um todo.

Por fim, identificou-se também uma lacuna nos dados de estatística pesqueira local e sazonal. Estes são escassos, de difícil acesso e com resolução temporal insuficientes para caracterizar a variabilidade sazonal da região. São necessários levantamentos regionais sistemáticos de dados de desembarques que incluam além da pesca industrial, a pesca artesanal, para ampliação do conhecimento do funcionamento dos ecossistemas. 


\section{REFERÊNCIAS BIBLIOGRÁFICAS}

ALLEN, R.R., 1971. Relation between production and biomass. J. Fish. Res. Board Can. V. 28, p. 1573-1581.

ALLEN, T.F.H.; STARR, T.B., 1982. Hierarchy: perspectives for ecological complexity. University Chicago Press. 310p.

ANGELINI, R. \& PETRERE JR., M., 1996. The ecosystem of Broa reservoir, São Paulo State, Brazil, as described using ECOPATH. NAGA, v. 19, n. 2. p. 3641.

ANGELINI, R. \& GOMESL.C., 2008. A arte da modelagem. In: O artesão de ecossistemas: construindo modelos com dados. Angelini, R. e Gomes, L.C. (organizadores). Maringá: Eduem, 2008.

ANGELINI, R., 2002. Bases para a aplicação da teoria da informação em ecossistemas, com ênfase na ascendência. Acta Scientiarum. Biological Science, Maringá, V.24, n², p.275-283.

ANONIMO, 1999. Programa de manejo Reserva de la Biosfera la Encrucijada. Instituto Nacional de Ecología, México. 183 p.

AZEVEDO, P.J.S., 2004. Onze anos de produção pesqueira no Municipio de Arraial do Cabo - RJ, Brasil. Dissertação de mestrado. Universidade Federal Fluminense, Instituto de Biologia marinha. $91 \mathrm{p}$. 
BENDOR, T.; SCHEFFRAN, J. \& HANNON, B., 2009. Ecological and economic sustainability in fishery management: A multi-agent model for understanding competition and cooperation, Ecological Economics 68, pp. 1061-1073.

BERGER, W.H.; SMETACEK, V.S. \& WEFER, G., 1989. Ocean productivity and paleoproductivity- an overview. In: BERGER, W.H.; SMETACEK, V.S. \& WEFER, G.E. (Eds.), Productuvity of the Ocean: Present and past. Wiley, New York p. 1-35.

BROWN, P.C.; PAINTING, S.J. \& COCHRANE, K.L., 1991. Estimates of phytoplankton and bacterial biomass and production in the northern and southern Benguela ecosystems, South African Journal of Marine Science 11 (1991), pp. 537-564.

CARBONEL, C.A.A.H., 2003. Modelling of upwelling-downwelling cycles caused by variable wind in a very sensitive coastal system. Continental Shelf Research, 23, 1559-1578.

CASTELAO, R.M.; CAMPOS, E.J.D. \& MILLER, J.L., 2004. A modelling study of coastal upwelling driven by wind and meanders of the Brazil Current. J. Coast. Res. V.20, n. 3. p. 662-671.

CASTRO FILHO, B.M. \& MIRANDA, L.B., 1998. Physical Oceanography of the Western Atlantic Continental Shelf located between $4^{\circ} \mathrm{N}$ and $34^{\circ} \mathrm{S}$ Coastal Segment (4,W). In: The Sea. Vol. 11.Oxford, John Wiley e Sons, v2, p.209-251. 
CASTRO-FILHO, B.M. \& GAETA, A.S., 2002. Projeto DEPROAS: um estudo multidisciplinar das intrusões da acas na plataforma sudeste. In: I SIMPÓSIO BRAsILEIRO de OCEANOGRafia, São PaUlo (RESUMOS). CD.

CHEN, Z.Z.; QIU, Y.S., JIA, X.P., XU, S.N.O., 2008. Simulating fisheries management options for the Beibu Gulf by means of an ecological modelling optimization routine. Fisheries Research. 89:257-265.

CHRISTENSEN, V. \& PAULY, D., 1993. Trophic models of aquatic ecosystems. ICLARM Conf. Proc. 26: 390 p.

CHRISTENSEN, V. \& PAULY, D., 1995. Fish production, catches and the carrying capacity of the world oceans. NAGA, the ICLARM Q. 18(3):34-40.

CHRISTENSEN, V. \& WALTERS, C.J., 2004. Ecopath with Ecosim: methods, capabilities and limitations. Ecol. Modell. v. 172, p. 109-139.

CHRISTENSEN, V.; WALTERS, C. \& PAULY,. D., 2000. Ecopath with Ecosim: a User's Guide, October Edition. Fisheries Centre, University of British Columbia, Vancouver, Canada and ICLARM, Penang, Malaysia. 130 p.

CHRISTENSEN, V. \& PAULY, D. 1992. ECOPATH II: a software for balancing steady state ecosystems models and calculating network characteristics, Ecol. Modell. v.61, p. 169-185.

CHRISTENSEN, V.; WALTERS C.J.; AHRENS R.; ALDER J.; BUSZOWSKI J.; CHRISTENSEN L. B., CHEUNG, W.W.L.; DUNNE, J.; FROESE, R. \& KARPOUZI, V., 2009. Database-driven models of the world's Large Marine Ecosystems. Ecological Modelling. 220:1984-1996. 
CHRISTENSEN, V.; WALTERS, C. \& PAULY, D., 2005. Ecopath with Ecosim: A User's Guide, Fisheries Centre, University of British Columbia 154pp.

CHRISTENSEN, V.; WALTERS, C.J. \& PAULY, D., 2004. Ecopath with Ecosim: A User's Guide. Vancouver: Fisheries Centre, University of British Columbia.

COLL, M.; SHANNON, L.J.; MOLONEY, C.L.; PALOMERA, I. \& TUDELA, S. 2006. Comparing trophic flows and fishing impacts of a NW Mediterranean ecosystem with costal upwelling systems by means of standardized models and indicators. Ecol. Modell. 220: 2088-2102.

CORBISIER, T.N., 2006. Trofodinâmica do ecossistema bentônico de plataforma continental da costa Sudeste do Brasil: Uso de isótopos estáveis de carbono e nitrogênio. Tese de livre docência. 116p.

DE LÉO, F.C. \& PIRES-VANIN, A.M.S., 2002. Estudo da composição e estrutura da comunidade da megafauna bêntica de plataforma continental nas regiões de Ubatuba e Cabo Frio (Projeto DEPROAS). In: I Simpósio Brasileiro de Oceanografia, São Paulo (resumos). CD.

DE LÉO, F.C. \& PIRES-VANIN, A.M.S., 2002. Fauna bêntica associada a blocos de algas calcárias na região de quebra de plataforma de Cabo Frio, RJ: aspectos da diversidade de microhabitats do fundo marinho (Projeto DEPROAS). In: I SIMPÓSIO BRASILEIRO de OCEANOGRAFIA, SÃo PAULO. CD.

DE LÉO, F.C.; PIRES-VANIN, A.M.S., 2005. Vertical distribution of benthic macrofauna in the Cabo Frio upwelling system (DEPROAS). In: II Congresso Brasileiro de Oceanografia, Vitória (resumos). CD. 
DUARTE, L.O. \& GARCIA C.B., 2004. Trophic role of small pelagic fishes in a tropical upwelling ecosystem. Ecological modeling, 172(2-4): 323-338.

FAO, 2002. The state of world's fisheries and aquaculture. Roma. $126 \mathrm{p}$.

FAO, 2005. Review of the state of world marine fishery resources, Roma. 20p.

Furtado, V.V.; CONTI, LA.; BARCELLOS, R.L. \& RODRIGUES, M., 2002. Considerações sobre o processo sedimentar na plataforma continental de São Paulo: uma revisão do Projeto DEPROAS. In: I SIMPÓSIO BRASILEIRO DE Oceanografia, São PaUlo (Resumos). CD.

GARCIA, S.M. AND COCHRANE, K.L., 2005. Ecosystem approach to fisheries: a review of implementation guidelines. ICES J. Mar. Sci. 2005 62: 311-318.

GASALLA, M.A. ; VELASCO, G. ; ROSSI-WONGTSCHOWSKI, C.L.D.B. ; HAIMOVICl, M. \& MADUREIRA, L.S.P., 2007 . Modelo de equilíbrio de biomassas do ecossistema marinho da Região Sudeste-Sul do Brasil, entre 100-1000 m de profundidade. EDUSP São Paulo: Instituto Oceanografico. v. 1.56 p.

GASALLA, M.A. \& ROSSI-WONGTSCHOWSKI, C.L.D.B., 2004. Contribution of ecosystem analysis to investigate the effects of changes in fishing strategies in the South Brazil Bight coastal ecosystem. Ecol. Modell. v.172, p. 283-306.

GASALLA, M.A. \& TOMÁS, A.R.G., 1998. Evaluation of the status of fisheries data collection and stock assessments problems in São Paulo, Southeastern Brazil. In: FUNK, F. et al., eds. Fishery StockAssessment Models. Alaska: Sea Grant College Program Report no. AK SG-98-01, University of Alaska Fairbanks. 
GASALLA, M.A., 2004. Impactos da pesca industrial no ecossistema da plataforma continental interna do sudeste do Brasil: a abordagem ecossistêmica e a integração do conhecimento. Tese de doutorado. Universidade de São Paulo, Instituto Oceanográfico. 276 p.

GERKING, S.D. 1994. Feeding ecology of fish. San Diego, Academic. 416p.

GIACOMINI, H.C. 2007. Os mecanismos de coexistência como vistos pela teoria ecológica. Oecologia Brasiliensis 11: 521-543.

GONZALEZ-RODRIGUEZ, E.; VALENTIN, J.L.; ANDRÉ, D.L. \& JACOB, A.S., 1992. Upwelling and downwelling at Cabo Frio (Brazil): Comparison of biomass and primary productivity response. Journal of Plankton Research, v.14, n. 2. p. 289-306.

GUÉNETTE, S.; HEYMANS, S.J.J.; CHRISTENSEN, V. \& TRITES, A.W., 2006. Ecosystem models show combined effects of fishing, predation, competition, and ocean productivity on Steller sea lions (Eumetopias jubatus) in Alaska. Can. J. Fish. Aquat. Sci. ,63(1 1): 2495-2517.

GUENTHER-SOARES, M., 2006. Efeito de fontes distintas de eutrofização, antrópica e natural, na estrutura de tamanho do fitoplâncton e na relação entre a produção primária e bacteriana: estudos na Baía de Guanabara e na região de ressurgência de Cabo Frio, RJ. Tese de Doutorado. Universidade de São Paulo, Instituto Oceanográfico. 208p.

HEYMANS, J.J. \& BAIRD, D., 2000. Network analysis of the northern Benguela ecosystem by means of NETWRK and ECOPATH. Ecological Modelling, $131(2-3): 97-119$ 
Heymans, J.J., Sumaila, U.R., Christensen, V., 2009. Policy options for the northern Benguela ecosystem using a multispecies, multifleet ecosystem model. Progress in Oceanography.

HILBORN, R. \& WALTERS C.J., 1992. Quantitative Fisheries Stock Assessment: Choice, Dynamics and Uncertainty. Chapman and Hall, New York. 570 p.

HOFFMANN, D.S., 2001. Conversando com Robert E. Ulanowicz. Episteme, v.12, p. 13-22.

IBAMA, 2002. Relatório anual de estatística pesqueira de 2001. www.ibama.org.br

IBAMA, 2003. Relatório anual de estatística pesqueira de 2002. www.ibama.org.br

IBAMA, 2004. Relatório anual de estatística pesqueira de 2001 e 2002. www.ibama.org.br

JARRE-TEICHMANN, A., \& PAULY, D., 1993. Seasonal changes in the Peruvian upwelling ecosystem. Pages 307-314 In: CHRISTENSEN, V. \& PAULY, D. (eds.) Trophic models of aquatic ecosystems. ICLARM Conference Proceedings Volume 26. International Center of Living Aquatic Resources Management, Manila, Philippines.

JARRE-TEICHMANN, A.; SHANNON, L.; MOLONEY, C. \& WICKENS, P., 1998. Comparing trophic flows in the Southern Benguela to those in other upwelling ecosystems. In: PILLAR, S.; MOLONEY, C.; PAYNE, A.; SHILLINGTON (Eds.), Benguela Dynamics. S. Afr. J. Mar. Sci. v.19, p. $391-$ 414. 
JORGENSEN, S.E., 1994. Fundamentals of Ecological Modelling. Elsevier. 628 p.

KAMPEL, M., 2003. Estimativa da produção primária e biomassa fitoplanctônica através de sensoriamento remoto da cor do oceano e dados in situ na costa sudeste brasileira. Tese de doutorado. Universidade de São Paulo, Instituto Oceanográfico, 272 p.

KATSURAGAWA, M.; MATSUURA, Y.; SUZUKI, K.; DIAS, J.F. \& SPACH, H.L., 1993. O Ictioplâncton ao largo de Ubatuba, SP: composição, distribuição e ocorrência sazonal (1985-1988). Publ. Esp. Inst. Oceanogr.,S.Paulo, 10:85121.

KEMPK, M. 1972. A plataforma continental da costa leste brasileira, entre o Rio

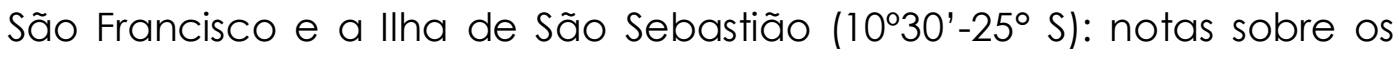
principais tipos de fundo. Anais do XXVI Congresso Brasileiro de Geologia, Belém. 211-23p.

KIØRBOE, T., 1993. Turbulence, phytoplankton cell size and the structure of pelagic food webs. Adv. Mar. Biol. 29: 1-72.

KLINE, T.C. JR. and PAULY, D., 1998. Cross-validation of trophic level estimates from mass-balance model of Prince William Sound using 15N/14N data. Pp. 693-702. Proceedings of the international Symposium on Fishery Stock Assement Models. Alaska Sea Grant College program Report. N98-01. Alaska Sea Grant, Fairbanks.

LEONTIEF, W., 1951. The Structure of the American Economy. Segunda Edição Ampliada. New York: Oxford University Press. 
LEVIN, S.A., 1970. Community equilibria and stability, and an extension of the competitive exclusion principle. The American Naturalist v.104, p. 413423.

LINDEMAM, R.L., 1942. The trophic-dynamic aspect of ecology. Ecology, v. 23, p. 399-418.

LONGHURST, A.R. \& PAULY D., 2007. Ecologia dos oceanos tropicais. Tradução: SACCARDO, S.A.; YAMAGUTI, N.; VAZOLER, A.E.M.; SOARES, L.S.H. \& TAVARES, I.D. , São Paulo, EDUSP, 419p.

LOPES, C.L.; ZANI-TEIXEIRA, M. L.; KATSURAGAWA, M.; OHKAWARA, M. H.; MENDES, M. F.; GOÇALO, C. G. \& DIAS, J. F., 2002. Distribuição vertical e abundância de larvas de peixes na região do Cabo Rio, RJ (PROJETO DEPROAS). In: I Simpósio Brasileiro de Oceanografia, São Paulo (resumos). CD.

LOPEZ, J.P. \& SOARES, L.S.H., 2003. Trofidinâmica dos peixes do ecossistema de plataforma da região oeste do Atlântico sul (Projeto DEPROASIOUSP/Pronex): resultados preliminares II. In: SICUSP XI Riberão Preto, São Paulo (resumos). CD.

MAJKOWSKY, J., 1982. Usefulness applicability of sensitivity analysis in a multispecies approach to fisheries management. In: PAULY. D.; MURPHY, G.I. (Eds) Theory and management of tropical fisheries. ICLARM, 149-166 p.

MANAVELLA, C. \& SOARES, L.S.H., 2003. Trofidinâmica dos peixes do ecossistema de plataforma da região oeste do Atlântico sul (Projeto DEPROAS- IOUSP/Pronex): resultados preliminares I. In: SICUSP XI, Riberão Preto, São Paulo (resumos). CD. 
MANN, K.H., 1982. Ecology of coastal waters: a systems approach. Blackwell Scientific Publications. Oxford. $322 \mathrm{p}$.

MATHISEN, O.A. \& SANDS, N.J.,1999. Ecosystem modeling of Becharof Lake, a sockeye salmon nursery lake in Southwestern Alaska, Ecosystem Approaches for Fisheries Management. Proceedings of 16 th Lowell Wakefield Fisheries Symposium University of Alaska Sea Grant. Fairbanks, AK, pp. 685-703 AK-SG-99-01.

MATSUURA, Y., 1986. Contribuição ao estudo da estrutura oceanográfica da região Sudeste entre Cabo Frio (RJ) e Cabo de Santa Marta (SC). Ciência Cult., Rio de Janeiro. V.38, n. 8. p.1439-1450.

MCCANN, K. \& HASTINGS, A., 1997. Re-evaluating the omnivory-stability relationship in food webs. Proceedings of the Royal Society: London B. 264: 1249-1254.

MEDINA, M.; ARANCIBIA, H. \& NEIRA, S., 2007. Un modelo trófico preliminar del ecosistema pelágico del norte de Chile (1 $\left.8^{\circ} 20^{\prime} S-24^{\circ} 00^{\prime} S\right)$, Invest. Mar. Valparaíso 35 (1) (2007), pp. 25-38.

MOLONEY, C.L.; JARRE, A.; ARANCIBIA, H.; BOZEC, Y.M.; NEIRA, S.; ROUX, J.-P. \& SHANNON, L.J., 2005. Comparing the Benguela and Humboldt marine upwelling ecosystems with indicators derived from inter-calibrate models. ICES J. Mar. Sci. v.62, n. 3. p. 493-502.

MOLONEY. C.L; JARRE, A.; ARANCIBIA, H.; BOZEC, Y.; NEIRA, S.; ROUX. J. \& SHANNON, L.J., 2005. Comparing the Benguela and Humboldt marine upwelling ecosystems with indicators derived from inter-calibrated models. ICES Journal of Marine Science, 62(3): 493-502. 
MOREIRA DA SILVA, P. D.C., 1973. A ressurgência de Cabo Frio. Publ. Inst. Pesq. Mar., 78: 1-56.

MULLER, F., 1992. Hierarchial approaches to ecosystem theory. Ecol. Modell., v. 63, p. 215-242.

MUTO, E.Y., 2004. Variações isotópicas de $13 \mathrm{C}$ e 15N de peixes demersopelágicos do ecossistema de plataforma ao largo de Cabo Frio (RJ) e Ubatuba (SP). Tese de doutorado. Universidade de São Paulo, Instituto Oceanográfico. p.

NEIRA, S. \& ARANCIBIA, H., 2004. Trophic interactions and community structure in the upwelling system off Central Chile (33-39[degree sign]S), Journal of Experimental Marine Biology and Ecology, 312: 349-366.

ODUM, E.P., 1971. Fundamentals of Ecology. $2^{\circ}$ edition, Philadelphia: W.B. Saunders, 574p.

ODUM, E.P., 1986. Energy in Ecosystem. In: Ecosystem theory and apllication. New Yourk: Wiley, J., 1986. P. 337-369.

ODUM, E. P., 1988. Ecologia. Rio de Janeiro, Guanabara. 434p.

ODUM, H.T., 1983. Systems ecology: An Introduction. John Wiley \& Sons, New York, 644p.

ODUM, W.E. \& HEALD, E.J. 1975. The detritus-based food web of an estuarine mangrove community. In L.E. Cronin, ed. Estuarine Research. p. 265-286. New York, Academic Press, Inc. 
PALOMARES, M.L. E PAULY, D., 1998, Predicting food consumption of fish populations as functions of mortality, food type, morphometrics, temperature and salinity. Mar. Freshwater Res. v. 49, p. 447-453.

PAULY, D., 1984. Fish population dynamics in tropical waters: a manual for use with programmable calculator. ICLARM Studies and Reviews, 8. Manila, Philippines. 325 p.

PAULY, D.; CHRISTENSEN, V.; DALSGAARD, J.; FROESE R. \& TORRES, F. Jr., 1998. Fishing dow marine food webs. Science 279: 860-863.

PAULY, D.; SORIANO, M. \& PALOMARES, M.L. 1993. Improved construction, parametrization and interpretation of steady-state ecosystem models. In: Christensen, V., Pauly, D. (Eds.), Trophic Models of Aquatic Ecosystem Models [S.I.]: ICLARM.

PIMM, S. L. 1982. Food Webs. Chapman and Hall, London. 219 pp.

PIRES-VANIN, A.M.S.; CORBISIER, T.N.; SOARES, L.S.H.; PETTI, M.A.V.; MUTO, E.Y. 2002. Relações tróficas no ecossistema marinho de Cabo Frio, RJ: análise de isótopos estáveis de carbono e nitrogênio (Projeto DEPROAS/Trofodinâmica). I Simpósio Brasileiro de Oceanografia, 1., 2002, São Paulo. Resumos, Cd.

PIRES-VANIN, A.M.S.; MATSUURA, Y., 1993. Estrutura e função do ecossistema de plataforma continental da região de Ubatuba, Estado de São Paulo: uma introdução. Publção esp. Inst. oceanogr., 10:1-8. 
Piroddi, C, Bearzi G, Christensen V., 2009. Effects of local fisheries and ocean productivity on the Northeastern Ionian Sea ecosystem. Ecopath 25 Years Conference Proceedings: Extended Abstracts pp.39-40.

POLOVINA, J.J. \& OW M.D., 1983. ECOPATH, A user's manual and programs listing. National Marine Fisheries Service. NOAA, Honolulu Adm. Rep. H 83-23: 46 pp.

POLOVINA, J.J. 1984. Model of a coral reef ecosystem. The ECOPATH model and its application to French Fregate Shoal. Coral Reefs, 3: 1-1 1.

POLOVINA, J.J., 1984. Model of a coral reef ecosystem. The ECOPATH model and its application to French Fregate Shoal. Coral Reefs 3: 1-11.

POLOVINA, J.J., 1985. An approach to estimating an ecosystem box model. Fish. Bull., U.S. 83(3):457-560.

POMEROY, L.R., \& DEIBEL, D., 1980. Aggregation of organic matter by pelagic tunicates. hmnol. Oceanogr. 25: 643-652.

PROZEE, 2005. Relatório Técnico Sobre o Censo Estrutural da Pesca Artesanal Marítima e Estuarina nos Estados do Espírito Santo, Rio de Janeiro, Paraná, Santa Catarina e Rio Grande do Sul. Fundação de Amparo à Pesquisa de Recursos Vivos na Zona Econômica Exclusiva, Itajaí. 151 p.

PUCCl, M.C., 2004. Dieta e planilha alimentar de seis espécies de peixes piscívoros da plataforma continental sudeste do Brasil. Dissertação de mestrado. Instituto Oceanográfico, Universidade de São Paulo. 136p. 
ROCHA, G.R.A.; GASALLA, M.A.; ROSSI-WONGTSCHOWSKI, C.L.D.B.; SOARES, L.S.H.; PIRES-VANIN, A.M.; MUTO, E.Y.; CERGOLE, M.C.; AIDAR, E.; MESQUITA, H.; GIANESELLA-GALVÃO, S.; VEGA-PEREZ, L.A.; JARRETEICHMANN, A., 1998. Quantitative Model of Trophic Interactions in the Ubatuba Shelf System (Southeastern Brazil). NAGA, The ICLARM Quarterly, 21 (4): 25-32.

ROCHA, G.R.A., 1998. Modelo quantitativo das interações tróficas da plataforma continental de Ubatuba (SP), Brasil. Tese de Doutorado, USP, $80 \mathrm{p.}$

ROCHA, G.R.A.; PIRES-VANIN, A.M.; ROSSI-WONGTSCHOWSKI, C.L.D.D. \& SOARES, L. S. H., 2008. Cap. 17. Abordagem ecossistêmica e modelos ecológicos. In: PIRES-VANIN, A.M.S. \& VERONESI, V. eds. Oceanografia de um ecossistema tropical: Plataforma continental interna de São Sebastião.

ROSSI-WNGTSCHOWSKI, C.L.D.B., VAZ-DOS-SANTOS, A.; COSTA, M.R.DA; FIGUEREDO, J.L; ÁVILA-DA-SILVA, A.O.; MOOURA, R.L. \& MENEZES, N., 2009. Peixes Marinhos In: BRESSAN,M.P.; KIERULFF,M.C.M.; SUGIEDA, A.M. Fauna ameaçada de Extinção no Estado de São paulo, Vertebrados. São Paulo: Fundação Parque Zoologico de São Paulo e Secretaria do Meio Ambiente, 645p.

SANTOS, M.A.G., 2004. Massas d'água, transporte e calor no Oceano Atlântico Sul através de um modelo numérico acoplado de circulação global. Dissertação de mestrado. Universidade de São Paulo, Instituto Oceanográfico, 87p. 
SHANNON, L.J.; MOLONEY, C.L.; JARRE, A. \& FIELD, J.G., 2003. Trophic flows in the southern Benguela during the 1980s and 1990s. Journal of Marine Systems, 39(1-2): 83-116.

SHANNON, L.J.; COCHRANE, K.L.; MOLONEY, C.L. \& FRÉON, P., 2004. Ecosystem approach to fisheries management in the southern Benguela: a workshop overview. African Journal of Marine Science, Volume 26, Number 1, June 2004, pp. 1-8(8).

SILVEIRA, I. C. A. DA; SCHIMIDT, A. C. K.; CAMPOS, E. J. D.; GODOI, S. S. DE \& IKEDA, Y., 2000. A Corrente do Brasil ao Largo da Costa Leste Brasileira, Rev. bras. Oceanogr., 48(2):171-183(C11).

SILVEIRA, I.C.A.; CASTRO FILHO, B.M.; MIRANDA, L.B. CALADO. L.; NONATO L.V. \& MATTOS, R.A., 2002. Condições oceanográficas de verão e inverno ao largo de cabo Frio dirante o projeto DEPROAS. Simpósio Brasileiro de Oceanografia, 1., 2002, São Paulo. Resumo, CD.

SOARES, L.S.H. \& MUTO, 2004. Ecologia trófica de Merluccius hubbsi na plataforma continental de Cabo Frio, RJ e Ubatuba SP: isótopos estáveis de $\mathrm{N}$ e $\mathrm{C}$ e dieta (Projeto DEPROAS - IOUSP/PRONEX) Simpósio Brasileiro de Oceanografia, 2., 2004, São Paulo. Resumo, CD.

SOARES, L.S.H.; MUTO, E.Y.; LOPEZ, J.P.; VERA, G.R. \& PUCCI, M.J. 2002. Comparação da ictiofauna da plataforma continental de Cabo Frio, RJ e Ubatuba, Sp (Projeto DEPROAS - IOUSP/PRONEX) Simpósio Brasileiro de Oceanografia, 1., 2002, São Paulo. Resumo, CD. 
STECH, J. L. \& LORENZZETTI, J. A., 1992: The response of the South Brazil Bight to the passage of wintertime cold fronts. J. Geophys. Res., 97 (C6), 99579520.

SUMIDA, P.Y.G.; YOSHINAGA, M.Y.; CIOTTI, A.M. \& GAETA, S.A. 2005. Benthic response to upwelling events off the SE Brazilian coast. Mar. Ecol. Prog. Ser., 291: 35-42.

TASCHETTO, A.S E WAINER, I.E.K.C. 2002. Avaliação do ciclo anual das variáveis de superfície marinha no Atlântico Sudoeste dentro do Projeto DEPROAS. Resumo, Simpósio Brasileiro de OCEanografia, 1 : 2002 : SÃo PAULO.

TELLES, M.D., 1998. Modelo trofodinâmico dos recifes em franja do Parque Nacional Marinho dos Abrolhos - Bahia, Tese de Mestrado, FURG, 150 p.

TOKESHI, M. (1999). SPECIES COEXISTENCE: Ecological and Evolutionary Perspectives. Blackwell Science, Oxford. 120p.

ULANOWICZ, R. \& PUCCIA, C., 1990. Mixed trophic impacts in ecosystems. Ceonoses 5: 7-16.

ULANOWICZ, R.E., 1997. Ecology, the ascendent perspective, Columbia University Press, New York. 201 p.

VALANTIN, J.L., COUTINHO, R., 1990. Modelling maximum chlorophyll in the Cabo Frio (Brazil) upwelling: a preliminary approach. Ecological Modelling, Volume 52: 103-113. 
VALENTIN, 2001. The Cabo Frio upwelling system, Brazil. In: Seeliger, U. e Kjerfv, B. eds. Costal marine ecosystem of latino America. Berlin, SpringerVerlag. P.97-105.

VALENTIN, J. L. 1984. Spatial structure of zooplankton community in the Cabo Frio region (Brazil) influenced by coastal upwelling. In Hydrobiologia, $v$. 113, p. 183-199. 1984.

VASCONCELLOS, M. \& GASALLA, M.A., 2001. Fisheries catches and carrying capacity of marine ecosystems in southern Brazil. Fisheries Research 50: 279-295.

VASCONCELLOS, M., 2000. Ecosystem impacts of fishing forage fishes: An analysis of harvest strategies for the Brazilian sardine. Tese de Doutorado, University of British Columbia, 187p.

VELASCO, G. \& CASTELO, J.P., 2005. An ecotrophic model of southern Brazil continental shelf fisheries scenarios for Engraulis anchoita (Pisces, Engraulididae). Atlântica 27, 59-68.

VELASCO, G. \& CASTELLO, J.P., 2006. Preliminary ecotrophic model of southern Brazil continental shelf and fisheries scenarios for Engraulis anchoita (Pisces, Engraulididae)., Atlântica 28 38-51.

VERA, G.R., 2006. Estudo trófico de Raneya brasiliensis (Kaup, 1856) no sistema costeiro da região Sudeste do Brasil. Dissertação de mestrado. Instituto Oceanográfico, Universidade de Saõ Paulo, 77p. 
WALTERS, C.J.; CHRISTENSEN, V.; PAULY, D., 1997. Structuring dynamic models of exploited ecosystems from trophic mass-balanced assessments. Reviews in Fish Biology and Fisheries, 7:139-172.

WILLIAMS, R.J.; MARTINEZ, N.D., 2004. Limits to trophic levels and omnivory in complex food webs: theory and data. The American Naturalist 163: 458468.

WOLFF, M. 1994. A trophic model for Tongoy Bay - a system exposed to suspended scallop culture (Northern Chile). J. Exp. Mar. Biol. Ecol. 182 149-168.

WOLFF, M.; KOCH, V. AND ISAAC, V., 2000. A trophic flow model of the Caete mangrove estuary (North Brazil) with considerations for the sustainable use of its resources. Estuarine, Coastal and Shelf Science, 50(6): 789-803.

WORM, B., E. G. BARBIER, N. BEAUMONT, J. E. DUFFY, C. FOLKE, B. S. HALPERN, J. B. C. JACKSON, H. K. LOTZE, F. MICHELI, S. R. PALUMBI, E. SALA, K. A. SELKOE, J .J. STACHOWICZ; WATSON, R., 2006. Impacts of biodiversity loss on oceanic ecosystem services. Science 314:787-314.

ZEMBRUSCKI, S.G. 1979. Geomorfologia da margem continental sul-brasileira e das bacias oceânicas adjacentes. In: Projeto REMAC. Geomorfologia da margem continental sul-brasileira e das bacias oceânicas adjacentes. Rio de Janeiro: PETROBRÁS-CENPES-DINTEP. Series: PROJETO REMAC, 7:129-177. 
Anexo 
Anexo 1: Referências dos parâmetros levantados para os grupos de peixes.

1. Lophius gastrophysus

A biomassa do L. gastrophisus foi calculada a partir dos dados de captura por área varrida coletados no projeto DEPROAS, o valor de P/B utilizado foi equivalente a $Z \mathrm{em}$ Perez et. al 2005, o Q/B foi calculado a partir dos parâmetros populacionais encontrados em Haimovicci e Velasco 2000.

2. Lulas

O valor inicial de biomassa das lulas foi estimado por Vasconcelos 2004 e foi adequada a área do modelo segundo dados de desembarque pesqueiro na região. O P/B utilizado foi encontrado em Peres 2002 (documentos do revizee) e o Q/B foi estimado pelo modelo de Vasconcelos e Gazalla 2001.

\section{Piscívoros pelágicos}

A biomassa inicial desse grupo foi estimada por Mourato (trabalho em preparação) e aumentada para o balanceamento por sugestão do próprio autor. O P/B é a partir de Z obtido em Vilela e Castelo 1993. E foi utilizado um valor para $\mathrm{EE}=0,44$ obtido em Gasalla et. al 2007.

4. Espada

Biomassa calculada a partir de dado de desembarque (IBAMA 2005), P/B apartir do valor de Z obtido por Magro 2006 e Q/B calculado pela fórmula empirica de Palomares e Pauly 1998.

5. Merluza

A biomassa desse grupo foi estimada com os dados de captura por área varrida obtidos no projeto DEPROAS, o P/B foi obtido através do valor de Z calculado por Vaz-dos-Santos 2005 e Q/B obtido pela fórmula empírica de Palomares e Pauly 1998.

6. Pescada

A biomassa desse grupo foi estimada com os dados de captura por área varrida obtidos no projeto DEPROAS, O P/B foi obtido através do valor de Z calculado por Castro et. al 2005 e Q/B utilizado foi o valor obtido para Cynocium striato por Vieira 1990.

\section{Piscívoros bentônicos}

A biomassa desse grupo foi estimada com os dados de captura por área varrida obtidos no projeto DEPROAS, O P/B foi obtido através do valor de $Z$ calculado por Haimovicci e Velasco 2000 e Q/B obtido pela fórmula empírica de Palomares e Pauly 1998.

\section{Piscívors bentófagos}

A biomassa desse grupo foi estimada com os dados de captura por área varrida obtidos no projeto DEPROAS, O P/B foi obtido através de uma média proporcional entre os valores de Z das espécies calculados por Andrade et al 2005 para Urophycis brasiliensis, Carneiro et al 2005 para Micropogonias furnieri e Haimovicci e Araujo 2005 para Paralichthys patagonicos, e Q/B obtido pela fórmula empírica de Palomares e Pauly 1998.

9. Raneya brasiliensis

A biomassa desse grupo foi estimada com os dados de captura por área varrida obtidos no projeto DEPROAS, O P/B foi calculado a partir de dados de M obtidos no "fish base" por não ser um espécie explorada economicamente foram ainda adotados valores de $\mathrm{EE}=0.95$ e $\mathrm{GE}=0,3$. 
Anexo 1:Continuação

\begin{tabular}{||l||}
\hline 10. Bentófagos II \\
A biomassa desse grupo foi estimada com os dados de captura por área varrida obtidos \\
no projeto DEPROAS, O P/B foi obtido através do valor de Z calculado por Andrade et al \\
2005 e Q/B obtido no modelo de Gasalla et. al 2007 . \\
\hline 11. Bentófagos I \\
A biomassa desse grupo foi estimada com os dados de captura por área varrida obtidos \\
no projeto DEPROAS acrecida pelos dados de desemparque do Pargus pargo que é \\
espécie alvo da pesca artesanal na região, O P/B foi obtido através do valor de Z \\
calculado por Castro 2000 e Q/B obtido por Vazoler 1991 . \\
\hline 12. Zooplanctivoros \\
A biomassa desse grupo foi obtida através de dados de desembarque do lbama (IBAMA \\
2005), O P/B foi obtido através do valor de Z obtidos Scarrado et al 2005 para Scomber \\
japonicus e Q/B obtido pela fórmula empírica de Palomares e Pauly 1998.
\end{tabular}

Anexo 1: Referências complementares dos parâmetros levantados para os organismos bentônicos.

\begin{tabular}{||l||}
\hline 1. Camarões \\
A biomassa dos camarões foi estimada pelo modelo. Os valores adotados para P/B, Q/B \\
e EE foram retirados de outros modelos (Rocha et al., 2003; Vasconcellos 2000 e Gasalla \& \\
Rossi-Wongthowiski 2004). \\
\hline 2. Bentos carnívoro \\
A biomassa do bentos carnívoro foi obtida por DeLéo e Vanin 2006, O P/B, Q/B e EE \\
utilizados foram obtidos em outros modelos (Rocha, 1998; Rocha et al 2007 e Gasalla e \\
Rossi-Wongshowiski 2004). \\
\hline 3. Bentos detritívoro/ depositivoro \\
A biomassa do bentos detritívoro e depositívoro foi obtida por Melina (tese) e DeLéo e \\
Vanin 2006, o P/B, Q/B e EE utilizados foram obtidos em outros modelos (Rocha, 1998; \\
Rocha et al 2007 e Vasconcelos e Gasalla, 2001) \\
\hline
\end{tabular}


Anexo 2: Dados iniciais levantados para imput no Modelo anual.

\begin{tabular}{lcccc}
\hline Grupo trófico & $B$ & $P / B$ & $Q / B$ & $E E$ \\
\hline Lophius gastrophysus & 0,17 & 0,3 & 2,1 \\
Lulas & 3,76 & 1,95 & 3,9 \\
Piscivoros pelágicos & 1,70 & 1,35 & 2 \\
Espada & & 0,72 & 2,46 \\
Merluza & & 0,95 & 2,96 \\
Pescadas & 0,19 & 1,23 & 5,4 \\
Piscívoros bentônicos & 0,36 & 1,38 & 3 \\
Comedores de invertebrados bentônicos e peixes & 0,43 & 0,70 & 3,38 \\
Raneya brasiliensis & 0,09 & 0,72 & 3,8 \\
Bentófagos I & 1,50 & 0,38 & 2 \\
Bentófagos II & 0,62 & 1,16 & 3,8 \\
Zooplanctófagos & 2,30 & 2,80 & 13,8 \\
Outros pequenos pelágicos & 2,01 & 3,19 & 11 \\
Sardinha & & 3,60 & 20,3 \\
Zooplâncton II & & 40,00 & 54 & 0,15 \\
Zooplâncton I & & 13,00 & 60 & 0,8 \\
Camarão & & 5,20 & 33,3 & 0,8 \\
Bentos carnívoro & 18,54 & 5,59 & 18,6 \\
Bentos depositívoro/detritívoro & 68,00 & 3,30 & 27,3 \\
Fitoplâncton & 29,65 & 115,70 & \\
Detrito & 11,23 & & \\
\hline B=Biomassa; P/B=produção por biomassa; Q/B=consumo por biomassa; EE= eficiência ecotrófica
\end{tabular}

